\title{
Vibration-Based Damage Detection of a Steel-Concrete Composite Slab Using Non-Model-Based and Model-Based Methods
}

\author{
Liang Fang $\mathbb{D},{ }^{1,2,3}$ Yun Zhou $\mathbb{D}^{1,2}$ Yunzhong Jiang, ${ }^{1}$ Yilin Pei, ${ }^{1}$ and Weijian $\mathrm{Yi}^{1,2}$ \\ ${ }^{1}$ College of Civil Engineering, Hunan University, Changsha 410082, China \\ ${ }^{2}$ Hunan Provincial Key Lab on Damage Diagnosis for Engineering Structures, Hunan University, Changsha 410082, China \\ ${ }^{3}$ College of Water Resource and Civil Engineering, Hunan Agricultural University, Changsha 410128, China
}

Correspondence should be addressed to Yun Zhou; zhouyun05@hnu.edu.cn

Received 8 March 2020; Revised 9 August 2020; Accepted 24 August 2020; Published 11 September 2020

Academic Editor: Paolo Castaldo

Copyright ( $\odot 2020$ Liang Fang et al. This is an open access article distributed under the Creative Commons Attribution License, which permits unrestricted use, distribution, and reproduction in any medium, provided the original work is properly cited.

This paper presents vibration-based damage detection (VBDD) for testing a steel-concrete composite bridge deck in a laboratory using both model-based and non-model-based methods. Damage that appears on a composite bridge deck may occur either in the service condition or in the loading condition. To verify the efficiency of the dynamic test methods for assessing different damage scenarios, two defect cases were designed in the service condition by removing the connection bolts along half of a steel girder and replacing the boundary conditions, while three damage cases were introduced in the loading condition by increasing the applied load. A static test and a multiple reference impact test (MRIT) were conducted in each case to obtain the corresponding deflection and modal data. For the non-model-based method, modal flexibility and modal flexibility displacement (MFD) were used to detect the location and extent of the damage. The test results showed that the appearance and location of the damage in defect cases and loading conditions can be successfully identified by the MFD values. A finite element (FE) model was rationally selected to represent the dynamic characteristics of the physical model, while four highly sensitive physical parameters were rationally selected using sensitivity analysis. The model updating technique was used to assess the condition of the whole deck in the service condition, including the boundary conditions, connectors, and slab. Using damage functions, Strand7 software was used to conduct FE analysis coupled with the MATLAB application programming interface to update multiple physical parameters. Of the three different FE models used to simulate the behavior of the composite slab, the calculated MFD of the shell-solid FE model was almost identical to the test results, indicating that the performance of the tested composite structure could be accurately predicted by this type of FE model.

\section{Introduction}

Steel-concrete composite bridges are used extensively in highway networks. In this type of bridge system, reinforced concrete (RC) decks are connected to steel girders to obtain the merits of both materials and to increase the rigidity of both the girders and the slabs. Shear connectors (headed studs) provide integrity to the composite bridge by increasing the composite rigidity for uniform actions under live loads and resisting horizontal shear at the girder-deck interface. However, deterioration of the connectors over several years will decrease the composite action, and cracks that occur under the service load due to insufficient strength or fatigue may result in increased damage; plus, settlement caused by increased traffic weights can induce or change the intrinsic forces in the bridge deck. Since all defects and damage can influence the load-carrying capacity of the bridge, early detection of structural damage in a bridge is therefore crucial to avoid life and economic losses due to catastrophic failures. To detect structural damage, traditional nondestructive techniques (NDT), such as ultrasonic methods, magnetic field methods, radiograph methods, eddy current methods, and thermal field methods, have been developed to identify local damage [1]. However, a new rapid nondestructive assessment technique needs to be developed for practical applications. Among the various methods, the vibration-based damage detection (VBDD) is preferred as it uses changes in modal curvature and natural frequencies to 
define damage probability functions [2]. When invisible damage occurs on a complicated structure such as a composite bridge deck with shear connectors, the VBDD method may be particularly well suited as a global testing method to determine the structural condition of the bridge. Because of the easy acquisition of vibration characteristics and global information on structural conditions [3], the VBDD method can assess the condition of an entire structural component when some portions of the structure remain inaccessible to inspection by common NDE methods. In addition, when visible damage appears on a composite deck, the damage detected by the vibration-based method can be investigated using the provided dynamic information.

The VBDD method detects changes in the dynamic characteristics (e.g., natural frequencies, modal shapes, and damping ratios), which can be regarded as a global response signature, resulting from changes in the stiffness, mass, and boundary conditions. It is a great challenge to develop robust algorithms with the ability to detect, locate, and quantify damage according to the measured dynamic responses of the structure. Some complex situations and conditions, such as boundary conditions, bond-slip occurrences, and substructure damage, would be reflected in the vibration signature. The advantage of the VBDD method is the continuous monitoring of the structural conditions and identifying the earliest occurrence of possible damage. The VBDD method comprises the following four levels that determine changes in dynamic structural characteristics [4]: (1) qualitatively indicating damage occurrences; (2) localizing spatial information; (3) estimating the extent of damage; and (4) predicting the actual safety of the structure. Modal parameters such as natural frequencies and mode shapes are frequently used as damage-sensitive features to identify damage [5,6]. Many applications of the VBDD method have been developed in the past two decades as presented by Doebling et al. [7] and Sohn et al. [8]. Moughty and Casas [9] provided an in-depth review of the development of modal-based damage-sensitive features (DSFs) in bridges and a synopsis of the challenges involved. They addressed the challenges by drawing upon advanced techniques outlined in recent literature. Yang et al. [10] proposed the extraction of bridge frequencies from the dynamic response of a moving test vehicle. They also verified the technique by a field test and presented a state-of-the-art review of the related research works conducted worldwide. The VBDD method can be classified into the non-modelbased method and the model-based approach. The biggest difference in these two methods lies in whether a calibrated finite element (FE) has been used in the data analysis or not. The non-model-based method utilizes dynamic properties in measurements to directly deduce the physical characteristics, which is also known as a damage fingerprint method. The model-based method uses dynamic properties to calibrate the initial FE model and then deduce the damaged physical parameters by comparing updated and baseline cases. Although the non-model-based method is much easier to apply since no time and effort need be spent on modeling and model calibration, it is harder to detect damage in some structures than with the model-based method.
For a steel-concrete composite deck, damage that occurs in the structure, such as the loosening of shear connections, changes in the boundary conditions, and the development of cracks caused by loading, changes the structural vibration characteristics. Several studies have attempted to detect damage in the connectors between steel-concrete composite girders, both in the laboratory and on actual projects. However, limited studies have focused on damage detection approaches for steel-concrete composite structures, and very little research has used the VBDD method to provide a satisfactory assessment of different damage cases for composite structures. Xia et al. [11] made the first attempt at detecting possible damage of shear connectors in slab-girder bridges through vibration methods. A 1:3 scale bridge model was constructed in a laboratory to test the suitability and efficiency of the VBDD methods. Since it was found that the local approach is more sensitive to identifying the local damage of shear connectors than global methods, the local approach was developed and applied to assess the condition of the shear connectors in a full-size slab-girder bridge [12]. It was concluded that the newly developed method is a more practical approach for detection of damaged connectors than the model updating technique. Dilena and Morassi [13] presented a Euler-Bernoulli model of a composite beam that accurately described the measured dynamic response of composite beams with either severe or intermediate levels of damage. A diagnostic technique based on frequency measurements was then applied to the suggested model, which provided positive results. Xu and Jiang [14] used a number of piezoelectric zirconate titanate (PZT) patches on the upper flange of a steel girder and concrete slab, and the corresponding electromechanical impedance was measured using an impedance analyzer before and after loosening the connection bolts. Allahyari et al. [15] investigated the dynamic characteristics of unfilled steel-concrete decks, including normal-weight high-strength concrete (HC) and lightweight high-strength concrete (LHC). It was concluded that the decks fabricated with plain concrete (DPC) and the decks fabricated with LHC (DLHC) had approximately similar serviceability, whereas DLHC can be more applicable than DPC due to lower weight. Zhang et al. [16] presented a non-model-based damage detection approach for bridge structures based on the phase trajectory change of multitype vibration measurements. The experimental study demonstrated that the proposed approach can be used to identify the shear connection failure in a composite bridge model subjected to moving loads. Wróblewski et al. [17] demonstrated a method to show how changes in energy transfer ratios (ETRs) could be used for damage detection and localization in steel-concrete composite beams.

The dynamic computer simulation technique was used by Shih et al. [18] to identify damage to slab-on-girder bridges. Based on that technique, they used modal flexibility change and modal strain energy change for damage localization of shear connectors. Results showed that their method was effective in damage assessment for slab-ongirder bridge superstructure. The autoregressive with exogenous input (ARX) models and the sensor clustering damage identification technique [19] were then adopted to 
identify the damage of a full-scale, five-girder bridge. Zhang et al. [20] used quantum-inspired genetic algorithms (QIGAs) to improve computational efficiency by transforming the scaling factor sign determination problem to an optimization problem. And an experimental example of a steel-concrete composite slab and numerical example of a three-span continuous rigid-frame bridge were studied to verify the effectiveness of the proposed method. Tan et al. [21] used the vibration characteristics and artificial neural network (ANN) to detect damage in composite slab-ongirder bridge structure. Wang et al. [22] proposed a sparse Bayesian model for structural damage detection based on the variational Bayesian inference (VBI) and delayed rejection adaptive Metropolis (DRAM) algorithms, and a laboratorytested frame was utilized to verify its effectiveness.

The developed signal processing technique has recently been proposed for damage identification of composite structures. Liu and De Roeck [23] proposed a damage indicator for identifying stud damage based on the local modal curvature and the wavelet transform modulus maxima. The efficiency of the damage indicator was investigated using numerical simulations that introduced varying levels of damage to the stud by decreasing the spring stiffness. Ren et al. [24] simulated different damage scenarios by removing some shear connectors in a bridge model, and a signal-based damage detection method, in which the damage feature was characterized by the wavelet packet energy changes, was used to identify damage in the shear connectors. Li et al. [25] proposed a dynamic damage detection approach based on the wavelet packet energy of cross-correlation functions from ambient vibration measurements to identify the damage of shear connectors in slab-on-girder bridges. Bao et al. [26] presented an improved Hilbert-Huang transform (HHT) algorithm for identifying time-varying systems and analyzing nonlinear structural responses with closely spaced modes. The robustness and effectiveness of this algorithm were verified using both numerical simulations and laboratory measurements of vibration data on a scaled concrete-steel composite beam model.

To overcome the limitation of visual-based and vibration-based approaches to access the shear connection in composite bridges, an innovative relative displacement sensor has been developed to directly measure the relative displacement between the slab and girder in composite bridges [27]. Continuous wavelet transform (CWT) and HHT [28] were used to analyze the measured dynamic responses and to identify the damage of shear connectors in a composite bridge model under moving loads. The results demonstrate that relative displacement is a better response quantity for structural health monitoring of composite bridges. Moreover, Dackermann et al. [29] presented a dynamic-based method for evaluating the connection systems of timber composite structures. The proposed dynamic method provided an alternative to traditional static load testing and used vibration measurements to derive a loss of composite action index.
Detecting minor structural damage at an early stage to prevent further structural degradation and potential progressive failure was of great importance for bridge condition assessment. However, the detection of damage in these structures is difficult because the baseline data of these structures, such as their design details and an accurate FE model, are usually not available. To overcome that, in this study, two kinds of VBDD methods, namely, model-based and non-model-based damage detection methods, were used for damage detection. The efficiency and reliability of the two detection methods were also described. To the best of the authors' knowledge, it was the first attempt to use both VBDD methods to detect the occurrence, location, and extent of the damage in a steel-concrete composite slab. The effectiveness of both methods was demonstrated in predicting damage of a composite bridge to enable early retrofitting and prevent bridge failure. Moreover, two different damage simulation strategies were carried out in the damage detection experiment, which enhanced the practicability of the experimental study. The aim of this study was therefore to assess the feasibility of applying VBDD to identify the different damage cases of a steel-concrete composite structure. To achieve this aim, a 1:3 scaled steel-concrete composite bridge model was built in the laboratory to investigate the possibility of using VBDD. Although the experiment was conducted in the laboratory, it should be emphasized that the proposed techniques can be applied to all types of short bridges in the field. The focus was on detecting small levels and different types of damage using a global vibration testing method combined with the elaborate proposed techniques. Five different cases were designed to simulate damage in the service state and in the loading state, and static and dynamic experiments were performed under different damage conditions. The removable bolts and supports were specially designed as the controllable damage, and different levels of loading were carried out to obtain the actual damage incrementally. Owning to using these damage simulation strategies, the interfacial bond-slip damage between the concrete and the steel girder was simulated effectively, which was rarely considered in previous studies. Damage of the concrete deck was evaluated using two different strategies. The first strategy was to assess the condition using the damage index method, which does not rely on an FE model, so the modal flexibility was directly obtained through a multiple reference impact test (MRIT). The second strategy was to detect the damage using the FE model. In this case, the calculation and analysis were performed using the Strand7 FE analysis package coupled with the MATLAB application programming interface (API) after the model was updated with the data from the static and dynamic experiments on the slab. It was the first attempt to use both model-based and non-model-based damage detection methods to detect the occurrence, location, and extent of the damage in the steel-concrete composite slab. The effectiveness of both methods was demonstrated, and the findings of this research will be useful in predicting damage of composite bridges to enable early retrofitting and prevent bridge failure. 


\section{Test Specimen and Defect Case Design}

2.1. Test Specimen. A 1:3 scaled steel-concrete composite deck model was designed and constructed to represent half of the span of Pennsauken Creek Bridge in New Jersey, USA. The specimen was constructed in Hunan Provincial Key Lab on Damage Diagnosis for Engineering Structures at Hunan University. The steel-concrete composite deck had dimensions of $4.00 \mathrm{~m} \times 2.05 \mathrm{~m}$ to fit within the available laboratory space. A $60 \mathrm{~mm}$ C30 concrete slab was connected to three Q235 I-girders by shear connectors. The cubic compressive strength of the concrete was $53.68 \mathrm{MPa}$, which was used to estimate the elastic modulus of $3.51 \times 10^{4} \mathrm{~N} / \mathrm{mm}^{2}$ based on the Chinese Code for the design of concrete structures (GB50010-2010) [30]. The HPB $300 \Phi 6 \mathrm{~mm}$ rebars in the concrete slab were arranged in double layers. The yield strength of the rebar was $307.84 \mathrm{MPa}$, and its ultimate strength was $429.01 \mathrm{MPa}$ according to the reinforcement tensile test. Three steel I-girders were connected at the middle and at both ends by steel channel diaphragms. The specimen was simply supported on adjustable bearings, which were 3 fixed supports and 3 rolling supports on each side. The specimen cross section and the dynamic test instrument layout are shown in Figure 1. Two types of connections were made on this specimen: headed studs and removable bolts. The removable bolts were designed to simulate damage and to then be reset to an undamaged state. The $13 \mathrm{~mm}$ diameter headed studs were welded onto the upper flange of the middle girder, while the $12 \mathrm{~mm}$ removable bolts connected the concrete slab to girder 1 and girder 3 by drilling holes in the upper flange of the steel girder. After the concrete was poured, the bolt sleeves were permanently fixed. The connection was then completed by threading the bolt through the bolt sleeve. The tensile strength of the bolt was $800 \mathrm{MPa}$ with a yield ratio of 0.8 . To design the removable bolts in an undamaged state, the bolts were tightly screwed into the bolt sleeves; in a damaged state, the bolts were simply unscrewed from the bolt sleeve and completely removed. The distribution of bolts and connectors is presented in Figure 2, and the detailed design information can be found in Jiang [31].

\subsection{Defect Cases in the Service Condition (Case 1 and Case 2).} Considering the appearance of corrosion and fatigue under unexpected overloading, two cases were designed to simulate different damage scenarios of a composite deck in the service condition. The possible defects in the service condition were simulated as shown in Figure 3. In Case 1, the steel support $\left(E=2 \times 10^{5} \mathrm{MPa}\right)$ at point $1^{\#}$ was replaced by a polyurethane panel rubber support $(E=60 \mathrm{MPa})$ to simulate a boundary condition deficiency, as shown in Figure 3(a). In Case 2 , the bolts between points $5^{\#}$ and $9^{\#}$ on girder 1 were loosened to simulate interfacial bond-slip damage between the concrete and the girder, as shown in Figure 3(b). The designed defect cases had no material damage on the concrete slab or on the steel girders. The specimen in the intact stage corresponding to the two defect cases was defined as reference case I (Ref Case I).
2.3. Damage Cases in the Loading Conditions (Cases 3, 4, and 5). The static load tests performed on the composite deck can be classified into two different procedures: the weight loading procedure in the undamaged state and the hydraulic loading procedure in the damaged state. The vertical deflections were measured by 15 displacement sensors along three longitudinal girders (denoted as D01-15). Fifteen strain gauges were used to measure the concrete strain (denoted as C01-15), which were attached at the $1 / 4,3 / 8$, and $1 / 2$ locations of the slab. Twenty-four strain gauges were installed on the steel girder; four strain gauges were installed at the $1 / 4$ and $1 / 2$ span locations of each steel girder, while three strain gauges were installed on the web of the girder, and one was installed at the bottom of the flange (denoted as ST01-24). The static stain data were recorded by TDS-530 data logger. The instrumentation layout is shown in Figure 4.

In the first loading procedure, the weights were stacked on different instrumentation points, except for the boundary supports, to measure the deflection of the composite deck in the undamaged state; this state was defined as reference case II (Ref Case II), as shown in Figure 5(a), and the static and dynamic data were used as the baseline for further analysis. In the second loading procedure, a multilevel hydraulic loading test was conducted on the composite deck with three loading-unloading cycles that increased until the deck lost carrying capacity, as shown in Figure 5(b). Three damage cases (Cases 3, 4, and 5) were defined according to the severity of the damage on the model under cyclic loading. The typical load-displacement and load-strain curves are shown in Figure 6. The three damage cases were classified as follows:

(1) Case 3: when the load was $10 \mathrm{kN}$, the strain increased linearly as the residual displacement remained at $9.5 \mathrm{~mm}$. The structure then remained in the elastic stage as it was unloaded, and visible cracks began to appear on the concrete deck near girder 1 .

(2) Case 4: when the load was continually increased to $178.13 \mathrm{kN}$, the steel strain showed obvious plastic deformation, especially along girder 1 , and the concrete strain gauge attached to the bottom surface of the concrete presented an obvious bilinear loadstrain relationship until the strain gauge failed. The stiffness of the structure obviously decreased with the appearance of new cracks around the three steel girders, and the residual displacement remained at $17.3 \mathrm{~mm}$. The load was increased until a moderate number of cracks appeared, and the damage accumulated and extended from the middle of the slab to the two sides of the supports.

(3) Case 5: when the load was $258 \mathrm{kN}$, the displacement increased rapidly until the bolts on girder 1 were broken by the interfacial shear force. The steel strain almost reached its ultimate strain, and the residual displacement remained at $92.5 \mathrm{~mm}$. In this stage, an obvious flexural deformation appeared, and the cracking range increased before the steel girder began to yield. The crack width continued to increase 


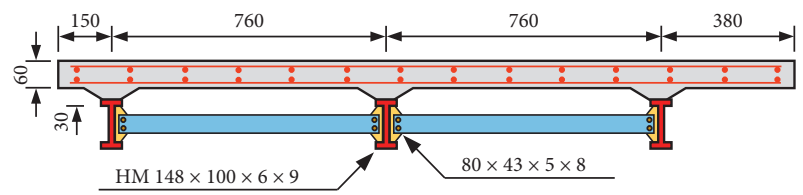

(a)

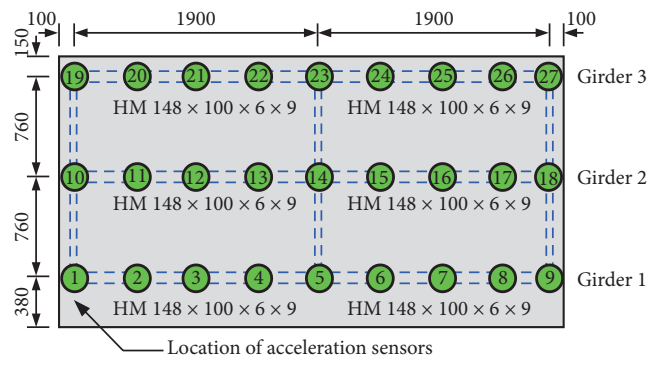

(b)

Figure 1: Steel-concrete composite slab model: (a) cross section; (b) instrumentation layout for the dynamic test (unit: mm).

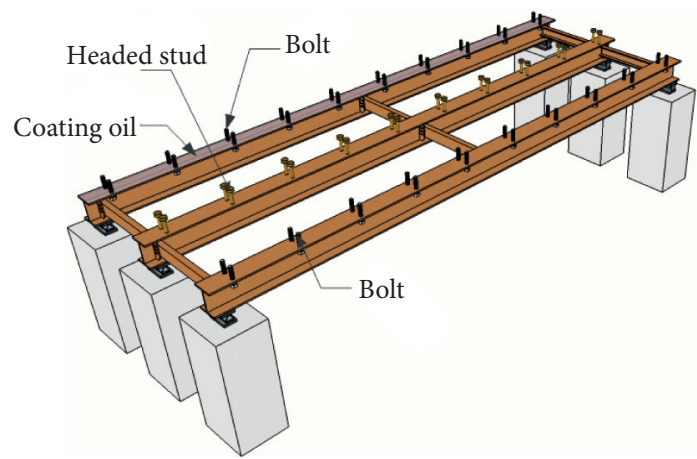

(a)

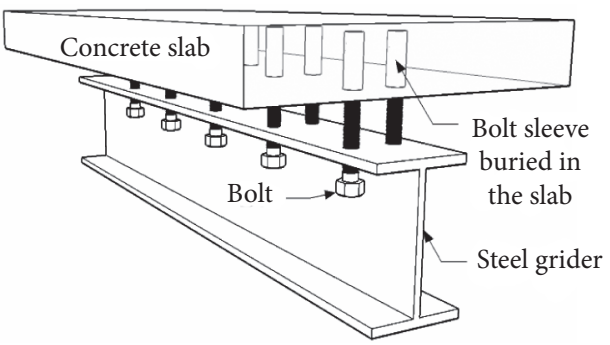

(b)

FIGURE 2: Design of composite slab connection: (a) distribution of the headed shear stud and bolt connections; (b) detailed configuration of the bolted connection along girder 1 and girder 3 .

and further penetrate the entire concrete deck. Finally, the bolt at the critical location was broken by the interfacial shear force, which was followed by spalling of the concrete. The typical crack patterns of the three damage cases are shown in Figure 7 . Because the cross section of composite deck was asymmetric, the crack patterns displayed eccentric characteristics.

\section{Dynamic Test and Experimental Modal Analysis}

3.1. Multiple Reference Impact Test. To determine the dynamic characteristics of the composite deck, a MRIT was used to generate modal information and further detect possible defects or damage in different cases. In the test, a PCB-086D20 sledge hammer (with a sensitivity coefficient of $0.23 \mathrm{mv} / \mathrm{N}$ and a frequency range of $0-6000 \mathrm{~Hz}$ ) was used to generate an impulse signal, and the vibration responses were collected by ICP-type KD1010L accelerometers (with a sensitivity of $10 \mathrm{mv} / \mathrm{ms}^{-2}$ and a frequency range of $0.5-7000 \mathrm{~Hz}$ ). Both of the signals were collected using Signal Calc DP730 data acquisition. The sampling frequency was set to $4096 \mathrm{~Hz}$ with a duration of $8 \mathrm{~s}$. To mitigate the ambient noise in the dynamic test, each point was impacted 5 times to generate average values. MRIT was performed in the undamaged state to obtain the modal data for the reference cases. The dynamic test was then conducted for each damage case to generate the modal information. In Case 1 and Case 2 , only girder 1 and girder 2 were tested.

3.2. Modal Parameter Identification. In MRIT, the measured dynamic signals of the force and response in the time domain were processed by fast Fourier transform (FFT) and then analyzed using the autopower spectrum and the crosspower spectrum in the frequency domain. $H_{1}$ estimation was then used to analyze the frequency response function (FRF); thereafter, the modal poles were extracted from the peak value of the FRF curves using the complex mode indicator function (CMIF) method. The peak-picking extraction of the eigenvalue from the singular value figure in Ref Case II is shown in Figure 8, and the first 9 identified mode shapes are shown in Figure 9.

The modal parameters, such as the frequencies and damping ratios, of defect Case 1 and Case 2 were compared with those of Ref Case I, as shown in Table 1. The natural frequencies of the specimen in different cases generally decreased when defect damage was introduced. Compared with the higher modes, the lower modes were more sensitive to slab defects. The first modal frequency in defect Cases 1 

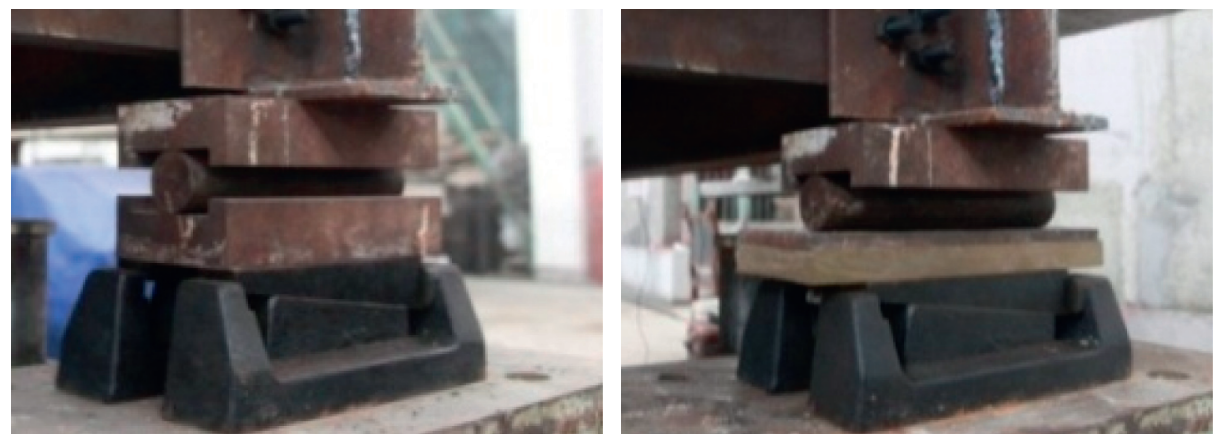

(a)
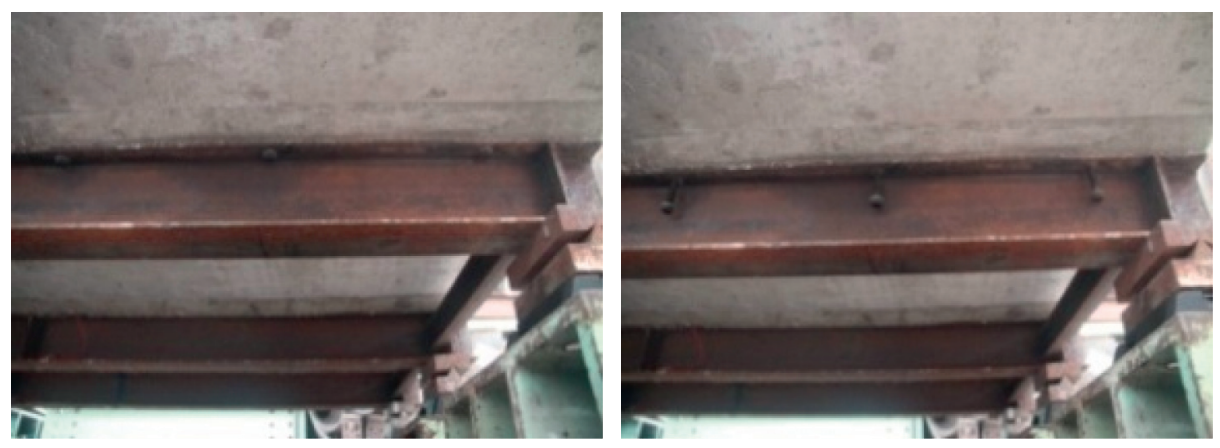

(b)

Figure 3: Two defect cases in the service condition: (a) Case 1; (b) Case 2.

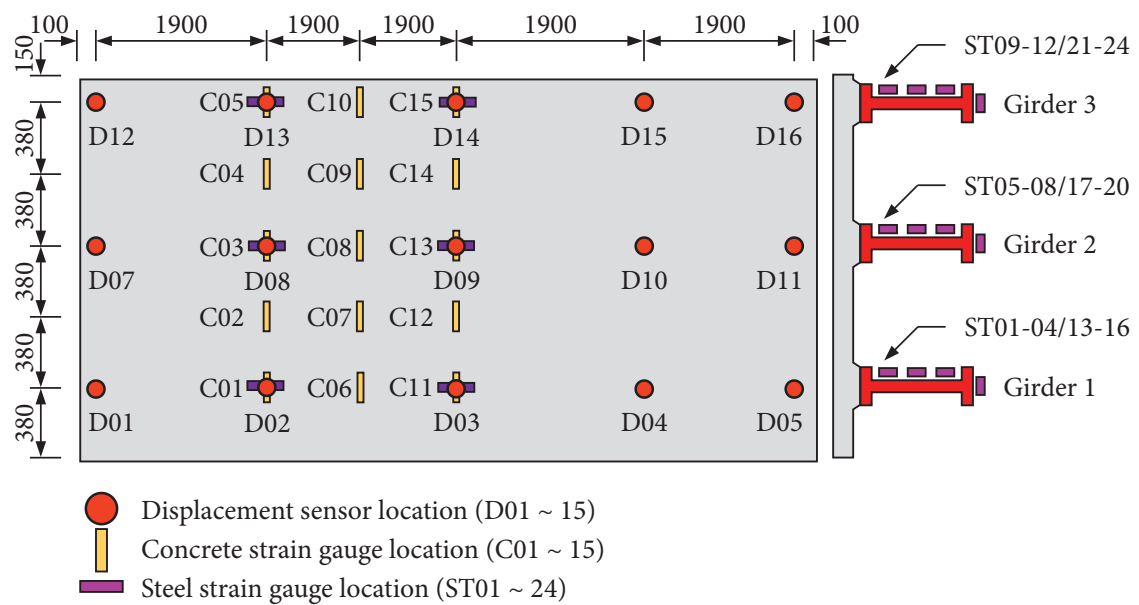

FIGURE 4: Instrumentation layout of static test.

and 2 decreased by $6.25 \%$ and $3.05 \%$, respectively. The modal frequencies were more sensitive to changes in the bearing stiffness due to the introduced defects in the model.

In Cases 3, 4, and 5, the modal parameters of the deck identified using the CMIF method are listed in Table 2. In general, with increasing damage, the natural frequencies decreased, while the damping ratios increased in the same mode. The frequencies and damping ratios of the lower modes changed more obviously than those of the higher modes, and the decreasing tendency of the modal frequencies and damping ratios followed the static damage severity. The first modal frequency in Cases 3, 4, and 5 decreased by $0.83 \%, 12.37 \%$, and $24.31 \%$, respectively, which were generally larger than the decreases due to the introduced defect.

\section{Damage Detection Using the Non-Model- Based Method}

4.1. Modal Flexibility by MRIT. The concept of structural modal flexibility was proposed by Clough and Penzien [32] as one of the common dynamic damage fingerprints [33]. Modal flexibility, which refers to a close approximation of flexibility extracted from modal test results, has been shown 


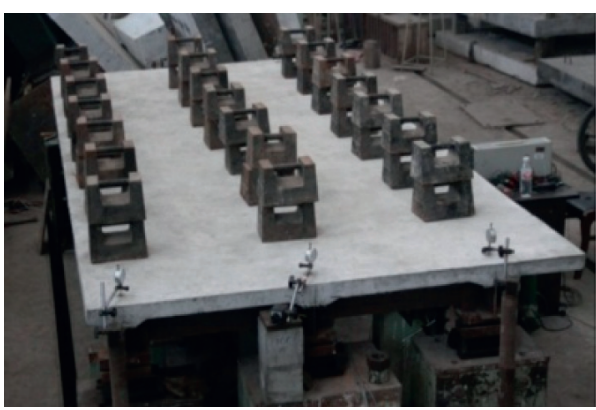

(a)

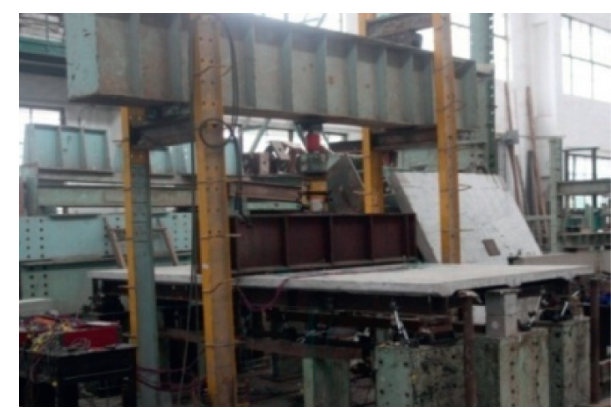

(b)

FIgURE 5: Pictures of the static tests: (a) weight loading test; (b) hydraulic loading test.

to be an excellent measure of flexibility if a sufficient number of modes are included [34]. It has been devised as a reliable experimental signature reflecting the existing condition of structures and can also serve as a stringent check to validate the accuracy and completeness of modal analysis results [35]. Structural modal flexibility and its changes are effective indices for evaluating structural performance and are more sensitive than frequency and mode shape. Through dynamic testing using MRIT, the modal flexibility can be directly determined from the impact and response data, and the variation of the modal flexibility can be used to detect damage without relying on an FE model. The two approaches for extracting modal flexibility were (1) the extraction of mass normalized mode shapes and modal frequencies and (2) the identification of a synthesized FRF matrix [34]. In the calculation strategy adopted by this study, the modal mass coefficient is directly extracted from the FRF measured by the MRIT. The FRF of the experiment can be written in partial fraction form:

$$
H_{\mathrm{pq}}(\omega)=\sum_{r=1}^{n}\left[\frac{A_{\mathrm{pqr}}}{\left(j \omega-\lambda_{\mathrm{r}}\right)}+\frac{A_{\mathrm{pqr}}^{*}}{\left(j \omega-\lambda_{\mathrm{r}}^{*}\right)}\right],
$$

where $H_{\mathrm{pq}}(\omega)$ is the FRF at point $p$ when the impacting takes place at point $q, j$ represents an imaginary number, $\omega$ is the frequency, $\lambda_{\mathrm{r}}$ represents the $r^{\text {th }}$ order pole of the system, and $A_{\mathrm{pqr}}$ is the $r^{\text {th }}$ order residue caught at point $p$ when the hitting takes place at point $q . A_{\mathrm{pqr}}=Q_{\mathrm{Ar}} \psi_{\mathrm{pr}} \psi_{\mathrm{qr}}$, where $Q_{\mathrm{Ar}}$ is the modal scale factor of the $r^{\text {th }}$ order mode, $\psi_{\mathrm{pr}}$ and $\psi_{\mathrm{qr}}$ represent the mode shape coefficient of the $r^{\text {th }}$ order mode at point $p$ and point $q$ respectively, and * represents complex conjugates.

Using the modal parameter estimation algorithm [35], the FRF between the degree of freedom (DOF) of $p$ and $q$ at $\omega=0$ was calculated and substituted into the previous expression as follows:

$$
H_{\mathrm{pq}}(\omega)=\sum_{r=1}^{m}\left[\frac{\psi_{\mathrm{pr}} \psi_{\mathrm{qr}}}{M_{\mathrm{Ar}}\left(-\lambda_{\mathrm{r}}\right)}+\frac{\psi_{\mathrm{pr}}^{*} \psi_{\mathrm{qr}}^{*}}{M_{\mathrm{Ar}}^{*}\left(-\lambda_{\mathrm{r}}^{*}\right)}\right],
$$

where $H_{\mathrm{pq}}(\omega)$ is the FRF at point $p$ due to the hitting input at point $q$ and $M_{\mathrm{Ar}}$ is the modal mass coefficient of the $r^{\text {th }}$ order mode; $M_{\mathrm{Ar}}=1 / Q_{\mathrm{Ar}}$.
The damage index method is a vibration-based method used for identifying damage in a structure, including the damage severity. After the modal flexibility matrix of the structure is obtained, it can be multiplied by the corresponding load force vector at each measurement point. The difference between the modal flexibility displacements (MFDs) of different cases is considered to be a damage index, as shown in the following equation:

$$
\operatorname{MFD}=\frac{\left|D_{d}-D_{r}\right|}{D_{r}} \times 100 \%,
$$

where $D_{d}$ is the MFD under the damage condition and $D_{r}$ is the MFD of the reference case.

4.2. Defect Detection. Two defect cases were analyzed using the CMIF method to select the peak values on the signal value curves; the modal flexibility can be estimated using equations (1) and (2) to predict the displacement value of the composite model under the applied weights. The displacement values obtained from the dynamic test analysis and measured by the static load test in the reference state were analyzed. Comparing the generated modal flexibility in Ref Case I and the defect cases, the MFD values of girders 1 and 2 are shown in Figure 10. In Case 1, when the defect occurred at point $1^{\#}$ of the support, the MFD values were sensitive to the induced damage location, and the maximum MFD occurred at point $1^{\#}$ with a difference of $119.6 \%$. In Case 2, the displacement values of girder 1 changed significantly when the bolts were loosened from point $5^{\#}$ to point $9^{\#}$ along half of girder 1 . The MFD values at point $8^{\#}$ and point $9^{\#}$ reached $22.1 \%$ and $89.8 \%$, respectively. Comparing the different defect cases in the service condition, the appearance and location of the damage due to changing the boundary conditions and loosening the bolts were effectively identified by the MFD values. This means that the non-model-based method can accurately identify both the damage and its location.

4.3. Loading Damage Detection. In Cases 3, 4, and 5, the displacements caused by the measured static test and the dynamic modal flexibility were compared for different cases. 


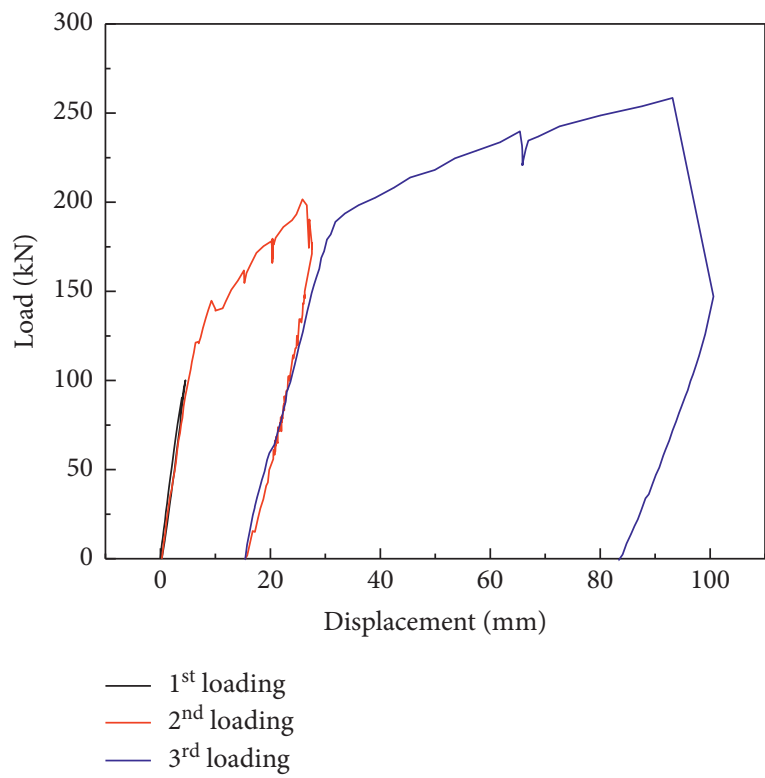

(a)

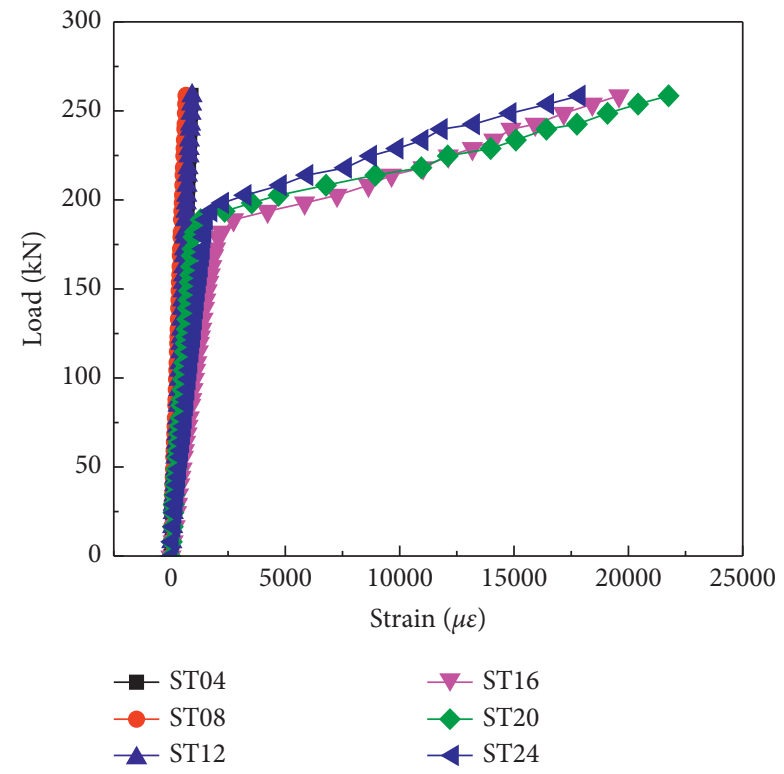

(b)

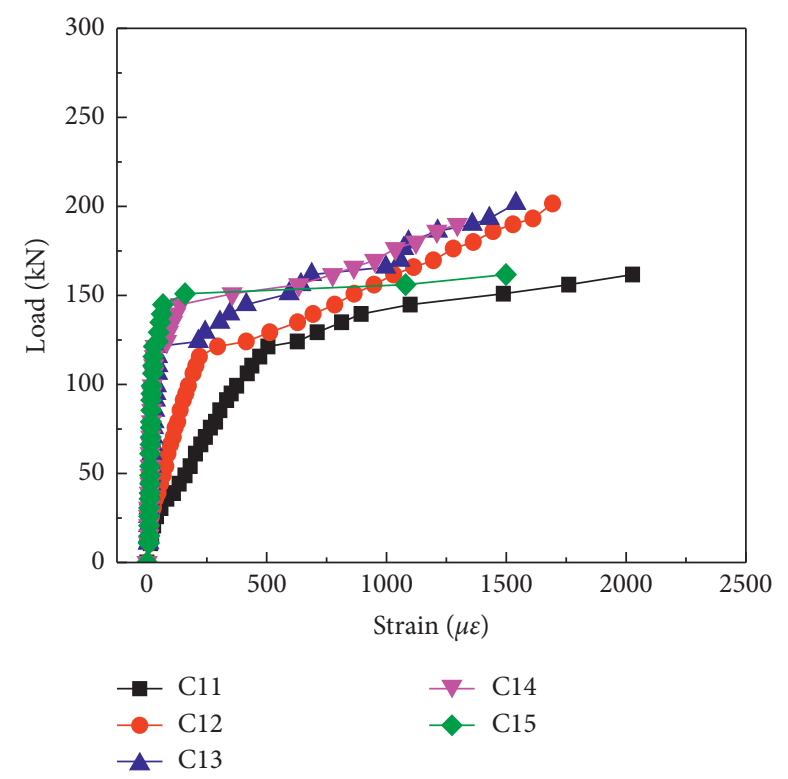

(c)

Figure 6: Measured displacement and strain on the structure: (a) measured vertical displacement at the middle span of girder 2; (b) measured steel strain at the $1 / 4$ and $1 / 2$ span locations of girder 1,2 , and 3 ; (c) measured concrete strain on the bottom surface at the $1 / 2$ span location.

The difference in MFD values between the damage cases and Ref Case II is shown in Figure 11. In Case 3, a 17.5\% difference in the MFD appeared at point $5^{\#}$, which is the exact position where the loading cracks first appeared; therefore, the MFD value changed more obviously on girders 1 and 2 than on girder 3. In Case 4, the MFD values of girder 2 are larger than those of girder 1 because the cracks extended from girder 1 to girder 2. However, the changes in the MFD value tended to be uniform at the other instrumentation points. In Case 5, with increasing applied load, the changes in the MFD value increased up to $92.8 \%$. At this stage, the visible damage on the specimen indicated ultimate failure of the structure. As a method that relies on input and output dynamic test data, the modal flexibility method along with the MFD value can effectively identify the location and extent of damage. It can be used for structural performance prediction and damage detection with reliable accuracy. The primary advantage of the proposed non-model-based approach is that it does not need baseline data (recorded with the structure in an undamaged state) or an accurate FE model. This method was suitable for damage detection with large modeling errors. 


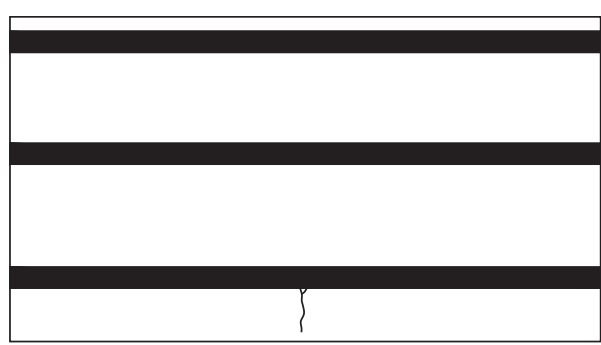

(a)

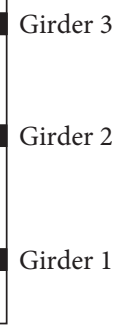

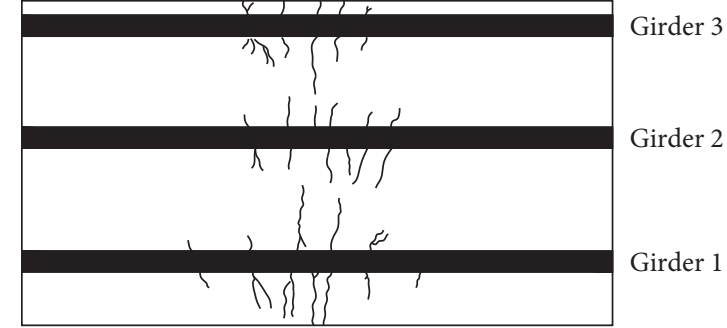

(b)

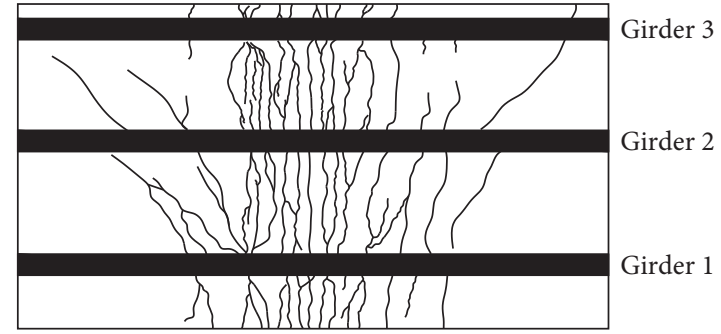

(c)

Figure 7: Crack patterns in different hydraulic loading cases: (a) Case 3; (b) Case 4; (c) Case 5.

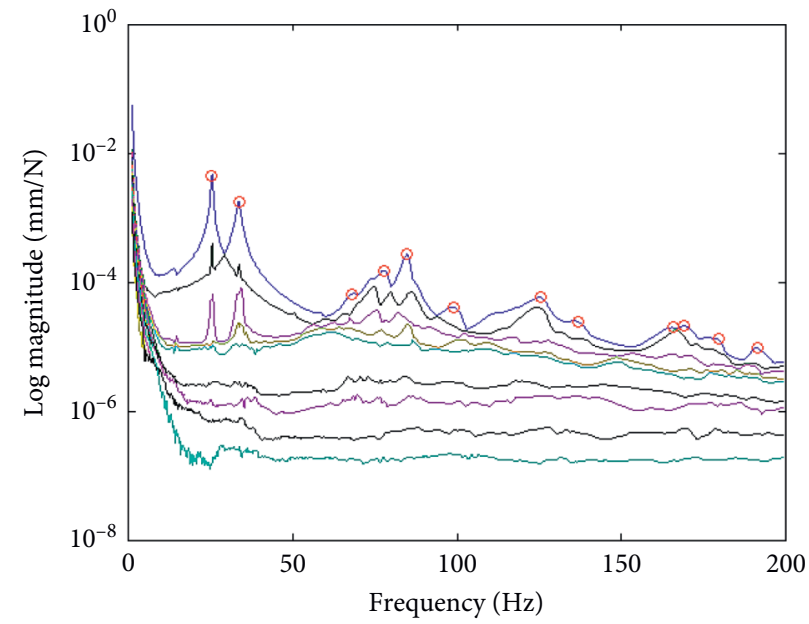

Figure 8: Peak-picking extraction in the singular value in Ref Case II.

\section{Damage Identification Using the Model- Based Method}

5.1. FE Model Construction. In addition to the non-modelbased method, an FE model can also be used to detect damage via a model updating technique. This model-based method depends on rational modeling to fully consider the detailed modeling configuration. A precise model can be used to simulate the mechanical behavior of the element and then relate it to the dynamic parameters. In order to obtain an accurate and reliable finite element model, an FE model was constructed using Strand7 software and computational simulation was conducted with different modeling strategies for the composite slab. Three different modeling strategies were used according to the test specimens shown in Figure 12: a beam-shell element model, a beam-solid element model, and a shell-solid element model. In the FE model, the rebar was considered to be a uniformly distributed material in the concrete, and the integrity model was adopted for the design of the concrete slab.

The interfacial adhesion of the two materials, the shear stiffness of the connectors, and the boundary conditions should all be considered in the model. Therefore, defining the link element between different components was very important in the modeling process. According to the different objects in elements, there were four kinds of link elements in three models: beam-support link element, beamslab link element, slab-slab link element, and connection 


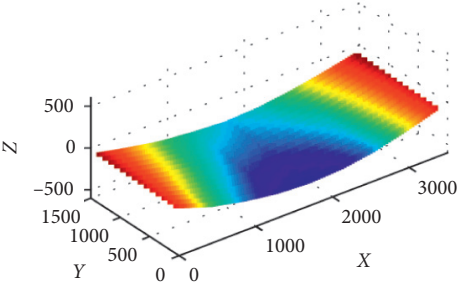

(a)

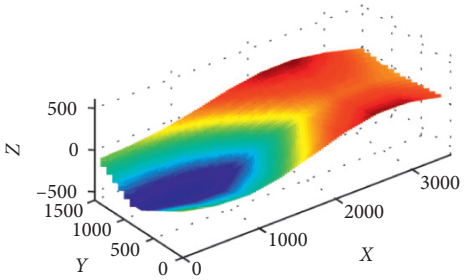

(d)

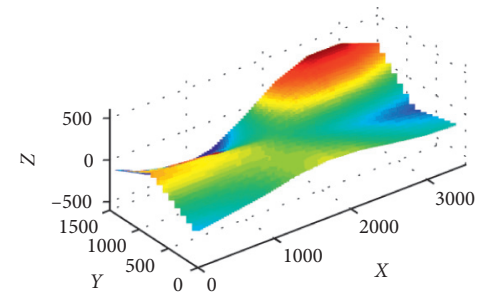

(g)

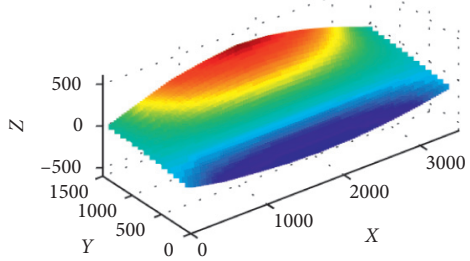

(b)

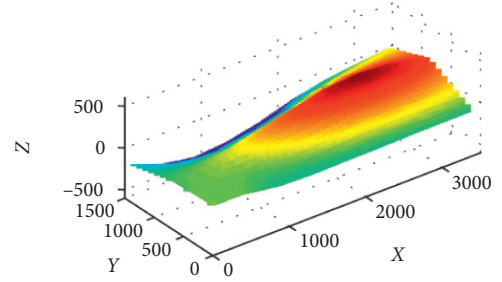

(e)

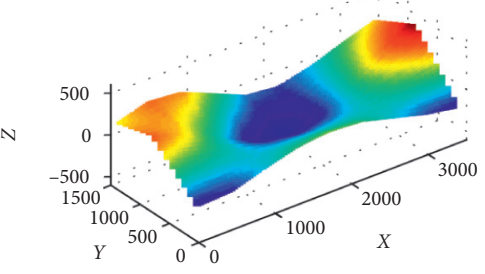

(h)

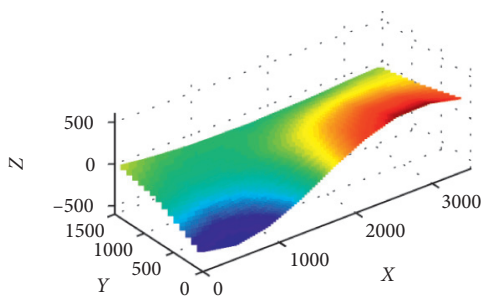

(c)

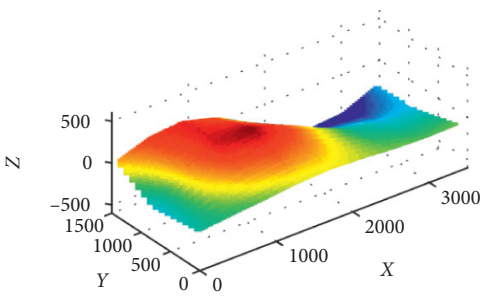

(f)

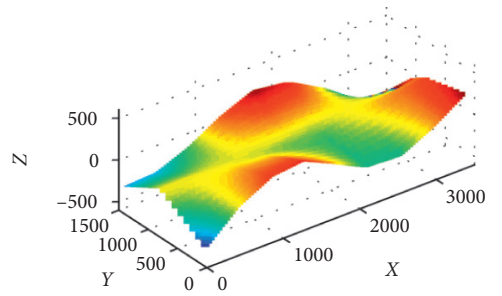

(i)

Figure 9: First 9 identified mode shapes in Ref CaseII: (a) $1^{\text {st }}$ mode; (b) $2^{\text {nd }}$ mode; (c) $3^{\text {rd }}$ mode; (d) $4^{\text {th }}$ mode; (e) $5^{\text {th }}$ mode; (f) $6^{\text {th }}$ mode; (g) $7^{\text {th }}$ mode; (h) $8^{\text {th }}$ mode; (i) $9^{\text {th }}$ mode.

TAвLE 1: Comparison of the identified modal information for Case 1 and Case 2.

\begin{tabular}{|c|c|c|c|c|c|c|c|c|}
\hline \multirow{2}{*}{ No. } & \multicolumn{2}{|c|}{ Ref Case I } & \multicolumn{3}{|c|}{ Case 1} & \multicolumn{3}{|c|}{ Case 2} \\
\hline & Freq. (Hz) & Damp. (\%) & Freq. (Hz) & Damp. (\%) & Diff. (\%) & Freq. (Hz) & Damp. (\%) & Diff. (\%) \\
\hline 1 & 20.01 & 2.47 & 18.76 & -3.08 & -6.25 & 19.40 & 2.71 & -3.05 \\
\hline 2 & 25.32 & 1.52 & 24.06 & -1.80 & 4.98 & 24.93 & 2.02 & -1.54 \\
\hline 3 & 31.74 & 1.72 & 30.89 & -1.67 & 2.68 & 31.37 & 1.54 & -1.17 \\
\hline 4 & 69.40 & 6.80 & 65.63 & -2.71 & 5.43 & 69.50 & 8.03 & 0.14 \\
\hline 5 & 74.54 & 4.11 & - & - & - & 73.75 & 3.05 & -1.06 \\
\hline 6 & 82.33 & 2.34 & 85.68 & -2.43 & 4.07 & 82.10 & 2.07 & -0.28 \\
\hline 7 & 110.61 & 4.60 & 103.40 & -3.76 & 6.52 & - & - & - \\
\hline 8 & 113.50 & 3.19 & 117.55 & -3.49 & 3.57 & 111.43 & 3.68 & -1.82 \\
\hline 9 & 154.39 & 2.75 & 149.80 & -3.80 & 2.97 & 150.13 & 3.69 & -2.76 \\
\hline
\end{tabular}

Note. Diff $=\left(f_{1}-f_{\mathrm{r} 1}\right) / f_{\mathrm{r} 1} \times 100 \%, f_{1}$ is the measured frequency of Case 1 or Case 2 , and $f_{\mathrm{r} 1}$ is the measured frequency of Ref Case I.

TABle 2: Comparison of the identified modal information for Cases 3, 4, and 5.

\begin{tabular}{|c|c|c|c|c|c|c|c|c|c|c|c|}
\hline \multirow{2}{*}{ Mode } & \multicolumn{2}{|c|}{ Ref Case II } & \multicolumn{3}{|c|}{ Case 3} & \multicolumn{3}{|c|}{ Case 4} & \multicolumn{3}{|c|}{ Case 5} \\
\hline & Freq. (Hz) & Damp. (\%) & Freq. (Hz) & Damp. (\%) & Diff. (\%) & Freq. (Hz) & Damp. (\%) & Diff. (\%) & Freq. (Hz) & Damp. (\%) & Diff. (\%) \\
\hline 1 & 25.30 & 0.99 & 25.09 & 1.47 & -0.83 & 22.17 & 1.91 & -12.37 & 19.15 & 2.21 & -24.31 \\
\hline 2 & 33.49 & 1.93 & 33.32 & 1.03 & -0.51 & 31.70 & 2.58 & -5.34 & 28.46 & 1.99 & -15.02 \\
\hline 3 & 67.76 & 1.75 & 67.56 & 2.26 & -0.30 & 65.24 & 2.31 & -3.72 & 63.70 & 2.07 & -5.99 \\
\hline 4 & 77.89 & 2.58 & 76.31 & 2.65 & -2.03 & 73.14 & 3.32 & -6.10 & 70.63 & 2.77 & -9.32 \\
\hline 5 & 84.71 & 1.43 & 83.09 & 1.25 & -1.91 & 80.02 & 1.54 & -5.54 & 79.74 & 1.65 & -5.87 \\
\hline 6 & 99.49 & 3.86 & 97.42 & 4.24 & -2.08 & 95.46 & 5.38 & -4.05 & 97.17 & 2.83 & -2.33 \\
\hline 7 & 125.37 & 3.12 & 121.13 & 2.82 & -3.38 & 119.56 & 3.10 & -4.63 & 117.25 & 2.52 & -6.48 \\
\hline 8 & 136.85 & 3.52 & 132.91 & 3.03 & -2.88 & 130.11 & 3.17 & -4.93 & 136.85 & 2.96 & 0.00 \\
\hline 9 & 165.26 & 3.33 & 167.44 & 3.25 & 1.32 & 162.74 & 2.87 & -1.52 & 161.51 & 3.61 & -2.27 \\
\hline
\end{tabular}

Note. Diff $=\left(f_{2}-f_{\mathrm{r} 2}\right) / f_{\mathrm{r} 2} \times 100 \%, f_{2}$ is the frequency of Cases 3,4 , or 5 , and $f_{\mathrm{r} 2}$ is the frequency of Ref Case II. 


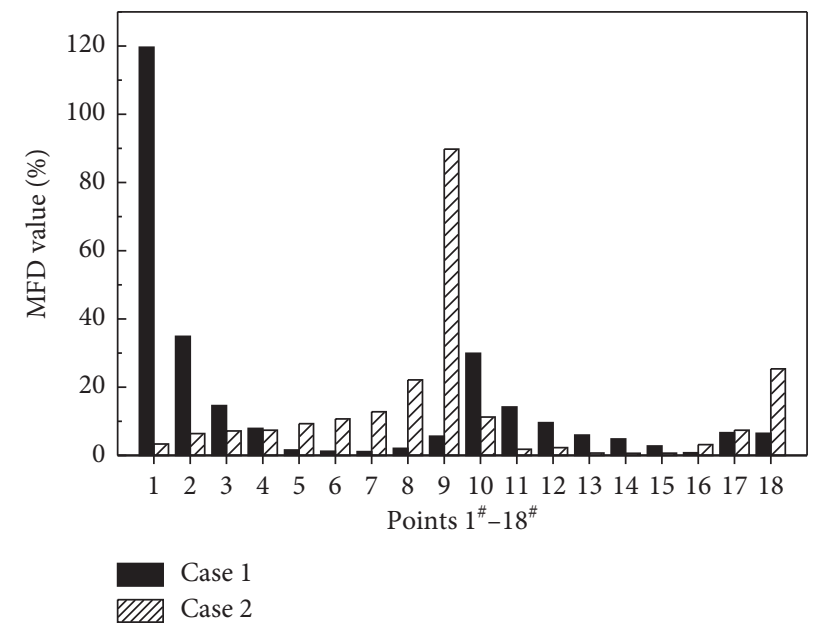

Figure 10: Relative difference of MFD in Case 1 and Case 2.

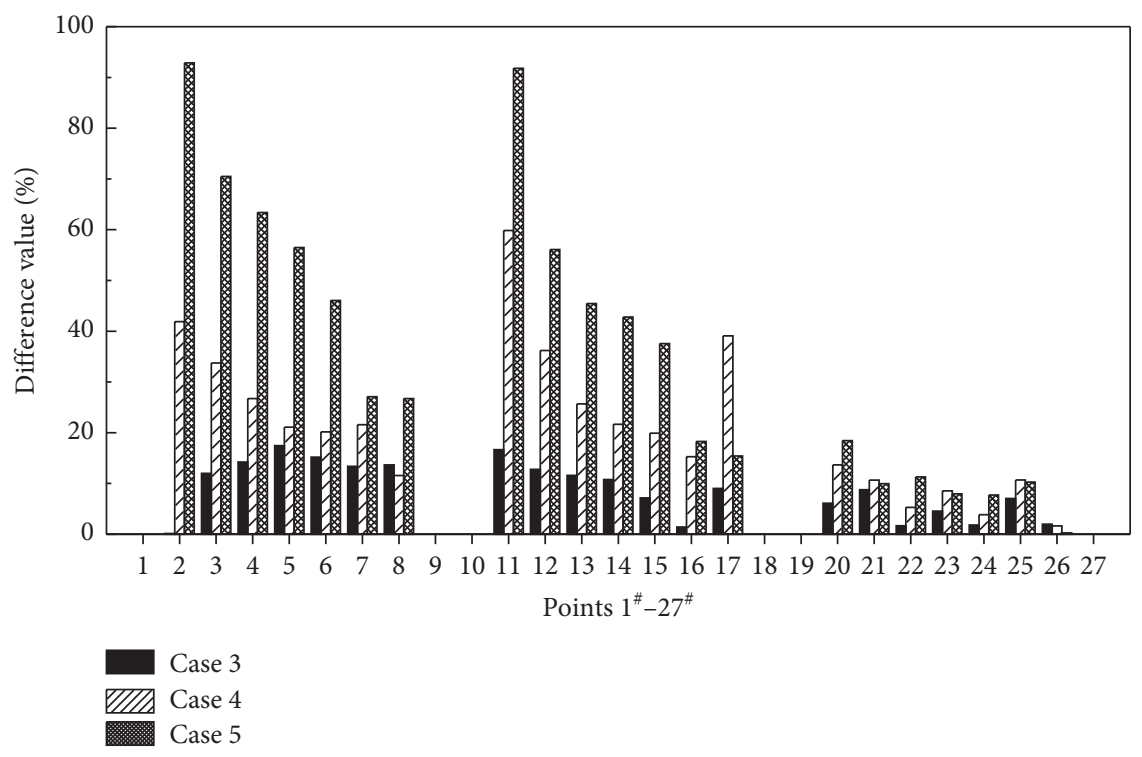

Figure 11: Relative difference of MFD in Cases 3, 4, and 5 (except for the support points).

element. The first three link elements were simulated by spring-damping elements which have different axial and lateral stiffness. The connection element was then modeled as an octahedron element, which consists of two springdamping elements and four rigid elements, as shown in Figure 13. The spring-damping element in the connector included only the axial stiffness of the spring. And the intersections of rigid elements were located in the vertical alignment nodes of the concrete slab and steel girder. The values for the spring stiffness are shown in Table 3.

The nominal physical properties of the concrete and the steel were used to model the deck. The uniaxial stress-strain relationship of concrete prescribed in GB50010-2010 [30] was employed to simulate the constitutive relationship of the concrete component (Figure 14(a)). The compressive strength of the concrete was $f_{c}=53.86 \mathrm{MPa}$, which resulted in an estimated elastic modulus of $E_{c}=3.51 \times 10^{4} \mathrm{MPa}$. Poisson's ratio was 0.2 , and the density was $2450 \mathrm{~kg} / \mathrm{m}^{3}$. To describe the stress-strain relationship of steel, the trilinear isotropic hardening model was employed addressing the strengthening stage after yielding and the descending stage after fracture (Figure 14(b)). The elastic modulus of the steel girder was $E_{s}=2.0 \times 10^{5} \mathrm{MPa}$, the density was $7850 \mathrm{~kg} / \mathrm{m}^{3}$, and Poisson's ratio was 0.3 .

The concrete damage plasticity (CDP) model is shown in Figure 15. In the CDP model, tensile cracking and compressive crushing of concrete are considered the main two failure mechanisms. Based on the smeared cracking approach, the damage or stiffness degradation is assumed to be uniformly distributed. The cracked concrete is 


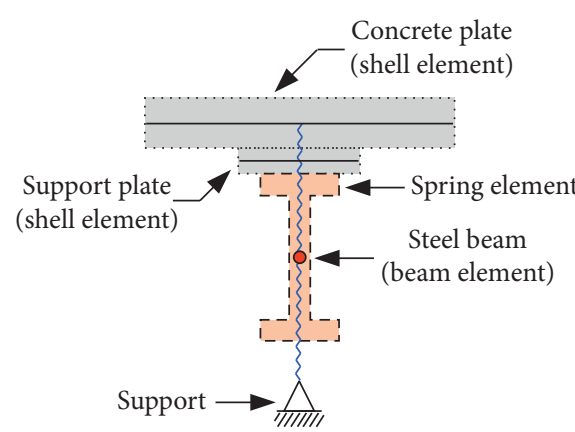

(a)

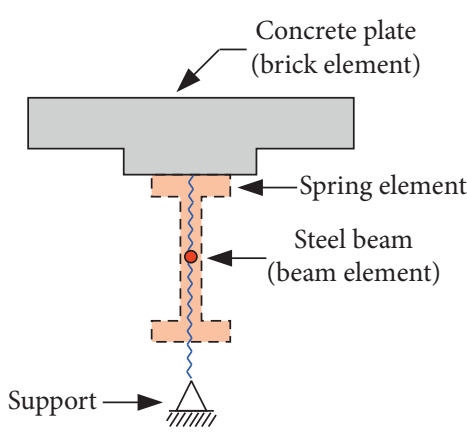

(b)

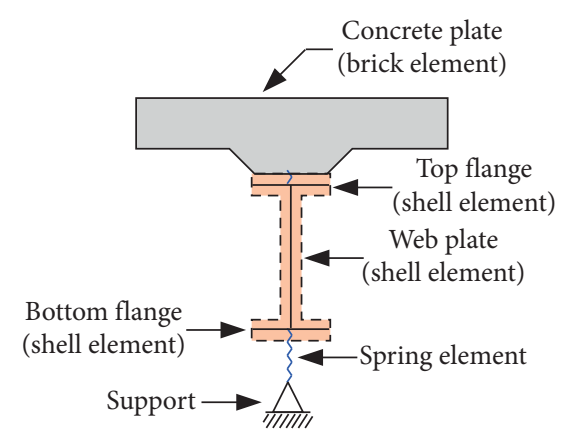

(c)

Figure 12: Comparison of the detailed configurations of three FE models: (a) beam-shell element; (b) beam-solid element; (c) shell-solid element.

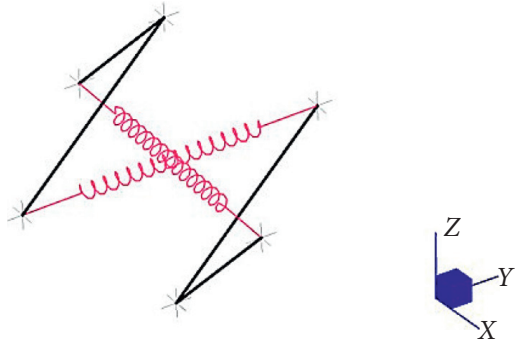

Figure 13: Octahedron element.

TABLE 3: Stiffness of the spring elements in the three models (unit: $\times 10^{6} \mathrm{kN} / \mathrm{mm}$ ).

\begin{tabular}{|c|c|c|c|}
\hline \multicolumn{2}{|c|}{ Model } & Axial stiffness & Lateral stiffness \\
\hline \multirow{4}{*}{ Beam-shell element model } & Beam-support & 2.0 & $10^{9}$ \\
\hline & Beam-slab & 1.02 & 0.5 \\
\hline & Slab-slab & 0.038 & 0.1 \\
\hline & Connection & 1.0 & 0 \\
\hline \multirow{3}{*}{ Beam-solid element model } & Beam-support & 2.0 & $10^{9}$ \\
\hline & Beam-slab & 1.02 & 0.5 \\
\hline & Connection & 1.0 & 0 \\
\hline \multirow{3}{*}{ Shell-solid element model } & Beam-support & 2.0 & $10^{9}$ \\
\hline & Beam-slab & 1.02 & 0.5 \\
\hline & Connection & 1.0 & 0 \\
\hline
\end{tabular}

regarded as an elastic orthotropic material with a reduced elastic modulus. The stiffness degradation is assumed to occur in the softening response in both compression and tension [36]. In this study, the corresponding parameters were defined as follows: the shape parameter was $K_{\mathrm{c}}=0.6667$, the dilation angle was $\psi=30^{\circ}$, the plastic potential eccentricity was $\varepsilon=0.1$, and the ratio of the biaxial stress to uniaxial stress was $\sigma_{\mathrm{b} 0} / \sigma_{\mathrm{c} 0}=1.16$ according to the study by Genikomsou and Polak [37].

The beam-shell model is relatively simple; the only difficulty lies in modeling the plate bracket due to the complex geometry of the height variations. The beam-solid model can overcome the difficulties of plate bracket modeling, but the interfacial bonding condition between the steel girder and concrete deck cannot be rationally simulated in the model. To overcome the difficulties of both of these modeling strategies, the shell-solid model reflects the real interface, geometry, and boundary conditions. To determine a suitable FE model, all three models were used for dynamic and static modal analysis, and the results were compared with the measured dynamic and static data. After the static tests were performed, the measured displacement and the displacement estimated by the FE model were compared, as shown in Figure 16. Because the shell-solid model has the previously mentioned advantages, its results are consistent with the measured results in the tested model. Therefore, the shell-solid model, as shown in Figure 17, was selected for the model updating analysis. In total, the shell-solid model 


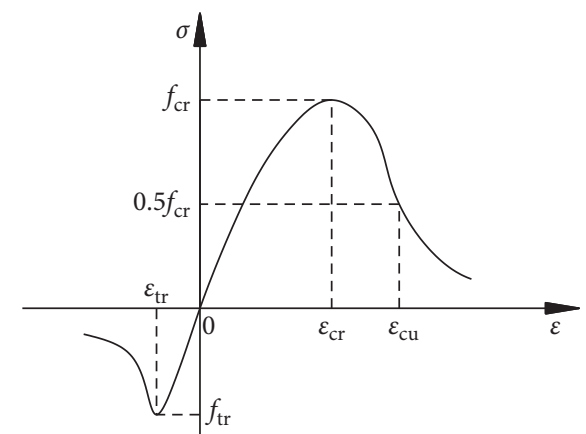

(a)

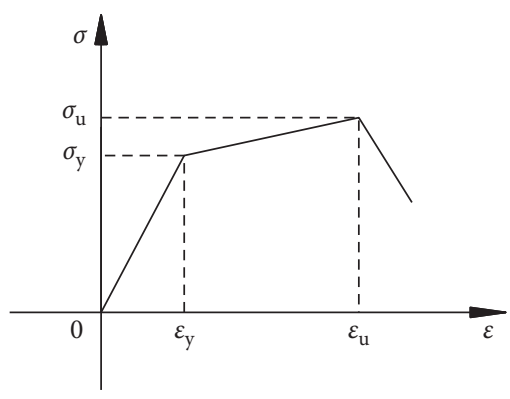

(b)

FIGURE 14: Stress-strain relationship of materials: (a) concrete; (b) steel reinforcement.

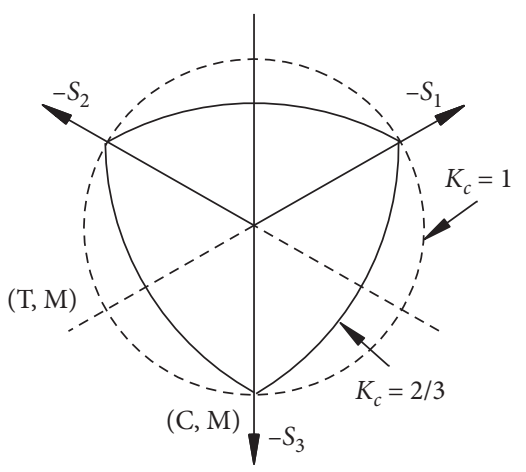

(a)

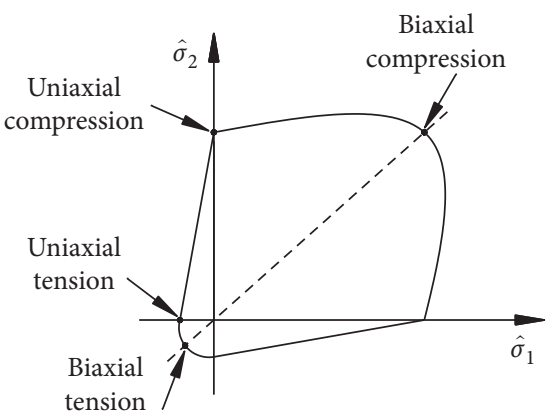

(b)

Figure 15: Illustration of concrete damage plasticity model: (a) deviatoric plane; (b) plane stress yield surface.

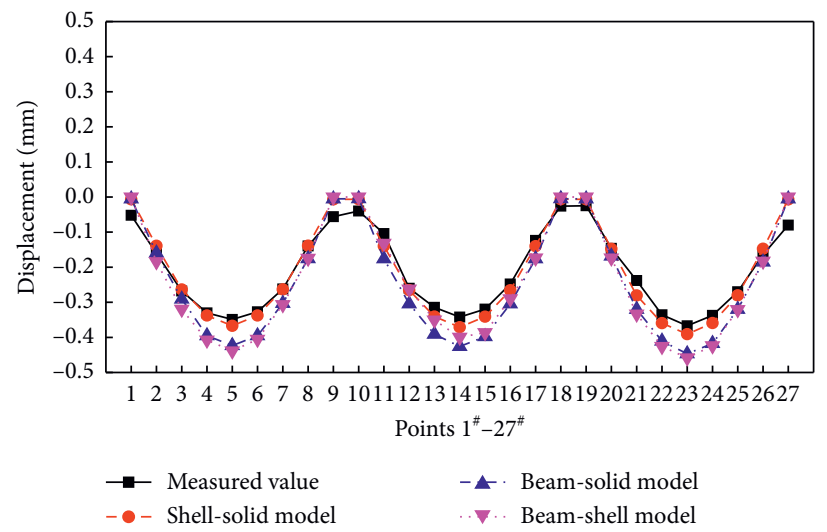

FIgURE 16: Comparison of the displacement results from the static test and the FE model analysis.

consisted of 1437 beam elements, 2400 shell elements, 9280 brick elements, and 264 link elements.

5.2. Sensitivity Analysis. In the damage identification techniques based on dynamic responses, the physical parameters of a structure in a healthy condition can be calibrated by minimizing residual errors. These models are then compared with any unknown (damaged) condition to obtain the corresponding residual errors. Any minor changes in these coefficients or residual errors are assumed to indicate damage in the structure. The physical parameters are estimated according to design drawings, standards, and the literature. Sensitivity analysis was used to analyze the 


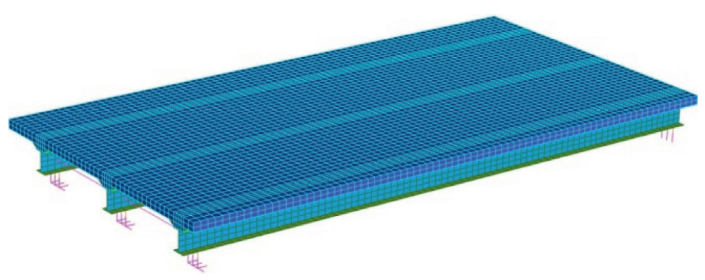

FIgURE 17: Shell-solid model.

influence of different physical parameters on the objective function. In the nominal FE model, five physical parameters were selected, and the data range was set as shown in Table 4. The objective function was built using the dynamic measurement data, as shown in equations (4), (5), and (6). The modes that have relatively large MAC values were used in the following objective function analysis. The sensitivity analysis results based on modal data, as shown in Figure 18, reveal that four physical parameters were sensitive to the objective function, while the beam-slab axial spring stiffness was not.

$$
\begin{aligned}
\operatorname{obj}_{\text {Modal }}(x) & =\frac{\sum_{i=1}^{n}\left(f_{\mathrm{i}}(x)+\left(1-\mathrm{MAC}_{\mathrm{i}}\right)\right)}{n}, \\
\operatorname{MAC}_{\mathrm{i}}(x) & =\frac{\left|\phi_{\mathrm{Ai}}^{T}(x) \phi_{\mathrm{Ei}}(x)\right|^{2}}{\left(\phi_{\mathrm{Ai}}^{T}(x) \phi_{\mathrm{Ai}}(x)\right)\left(\phi_{\mathrm{Ei}}^{T} \phi_{\mathrm{Ei}}\right)}, \\
f_{\mathrm{i}}(x) & =\frac{f_{\mathrm{E}}^{j}-f_{\mathrm{A}}^{j}(x)}{f_{\mathrm{E}}^{j}}
\end{aligned}
$$

where $E$ represents the measured data, $A$ denotes the analytical data from the Strand7 FE model, $f$ is the frequency, $\Phi$ is the mode shape, and $x$ is the updated parameter, such as the elastic modulus.

5.3. Model Updating for the Baseline FE Model. Finite element (FE) models were constructed on the basis of idealized engineering designs that may not truly represent all the physical aspects of an actual structure and therefore need to be updated to match the measured data [38]. In many studies, the sensitivity-based model updating method described by Mottershead et al. [39] has achieved great success. The FE model updating method considered in this paper was the iterative method, which involved the use of the sensitivity of the parameters to update the model.

An FE model, as illustrated in Figure 17, was built to detect the damage via a sensitivity-based model updating technique. Based on sensitivity analysis of the dynamic test results, the elastic modulus of concrete, the density of concrete, the axial stiffness of the bearing spring, and the axial stiffness of the connector spring were selected to update the model in the undamaged reference case to obtain a baseline model. The Strand7 FE analysis package was coupled with the MATLAB API for automated multiparameter model updating. The iterative results for multiple parameter identification based on the modal data are shown in
TABLE 4: Updating parameters for sensitivity analysis.

\begin{tabular}{lcccc}
\hline $\begin{array}{l}\text { Updating } \\
\text { parameter }\end{array}$ & $\begin{array}{c}\text { Lower } \\
\text { limit }\end{array}$ & $\begin{array}{c}\text { Upper } \\
\text { limit }\end{array}$ & $\begin{array}{c}\text { Distribution } \\
\text { pattern }\end{array}$ & Nominal value \\
\hline $\begin{array}{l}\text { Elastic } \\
\text { modulus } E\end{array}$ & $0.8 E_{0}$ & $1.5 E_{0}$ & Linear & $E_{0}=3.51 \times 10^{5} \mathrm{MPa}$ \\
$\begin{array}{l}\text { Density } \rho \\
\text { Axial }\end{array}$ & $0.8 \rho_{0}$ & $1.5 \rho_{0}$ & Linear & $\rho=2450 \mathrm{~kg} / \mathrm{m}^{3}$ \\
$\begin{array}{l}\text { stiffness of } \\
\text { support } \\
\text { spring } K_{1}\end{array}$ & $0.01 K_{1}$ & $100 K_{1}$ & Logarithmic & $K_{1}=200 \mathrm{kN} / \mathrm{mm}$ \\
$\begin{array}{l}\text { Axial } \\
\text { stiffness of }\end{array}$ & $0.01 K_{2}$ & $100 K_{2}$ & Logarithmic & $K_{2}=100 \mathrm{kN} / \mathrm{mm}$ \\
$\begin{array}{l}\text { beam-slab } \\
\text { spring } K_{2}\end{array}$ & & & & \\
$\begin{array}{l}\text { Axial } \\
\text { stiffness of } \\
\text { connector } \\
\text { spring } K_{3}\end{array}$ & $0.01 K_{3}$ & $100 K_{3}$ & Logarithmic & $K_{3}=100 \mathrm{kN} / \mathrm{mm}$ \\
\hline
\end{tabular}

Figure 19, while the objective function which converged after 67 iterative cycles is shown in Figure 19(b). The initial values and updated values are shown in Table 5.

The updated baseline model was then used for static and dynamic modal analysis. The calculated static displacements under a uniformly distributed load before and after model updating as well as the measured displacements are shown in Figure 20. The modal frequencies and mode shapes before and after model updating were compared with the dynamic test results shown in Table 6. Compared with the analysis results of the initial model, the static and dynamic analysis results using the updated model improved significantly.

5.4. Damage Detection in the Defect Cases. After the baseline model was obtained, the damage information was deduced by an additional model updating technique using the modal test results. In Case 1, the updating parameters were set as the stiffness of the six supports at points $1^{\#}, 9^{\#}, 10^{\#}, 18^{\#}, 19^{\#}$, and $27^{\#}$. In Case 2, all the bolts were divided into 6 regions, as shown in Figure 21, and the updating parameters were the average stiffness of the bolts in each region. The initial numbers of updating parameters in Case 1 and Case 2 were defined as a normalized stiffness of 1.0. The stiffness degradation distributions of the supports and the bolts after model updating are shown in Figure 22. Using the updated models, the correct locations of defective supports and bolts were identified. In Case 1 , the normalized stiffness of point $1^{\#}$ decreased to 0.131 due to the support changes. In Case 2, the stiffness value in the loosened bolt region between points $5^{\#}$ 


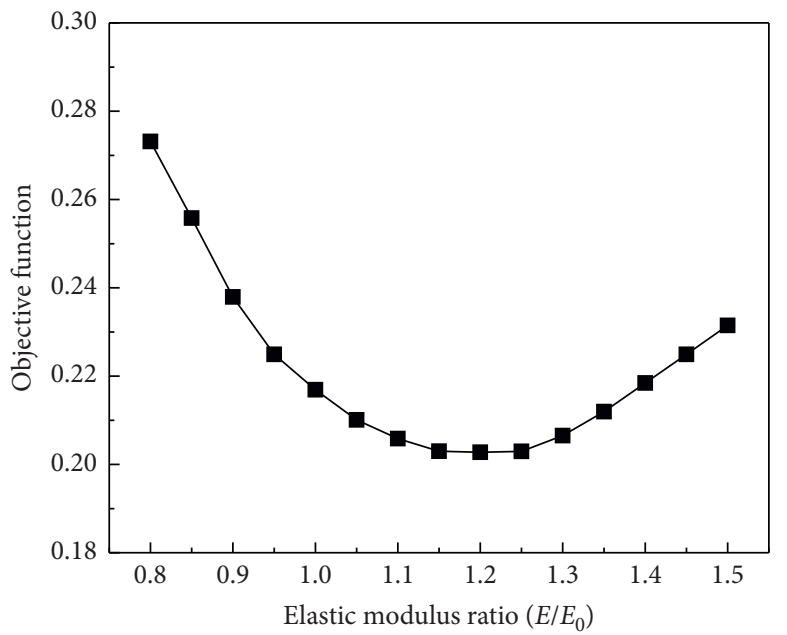

(a)

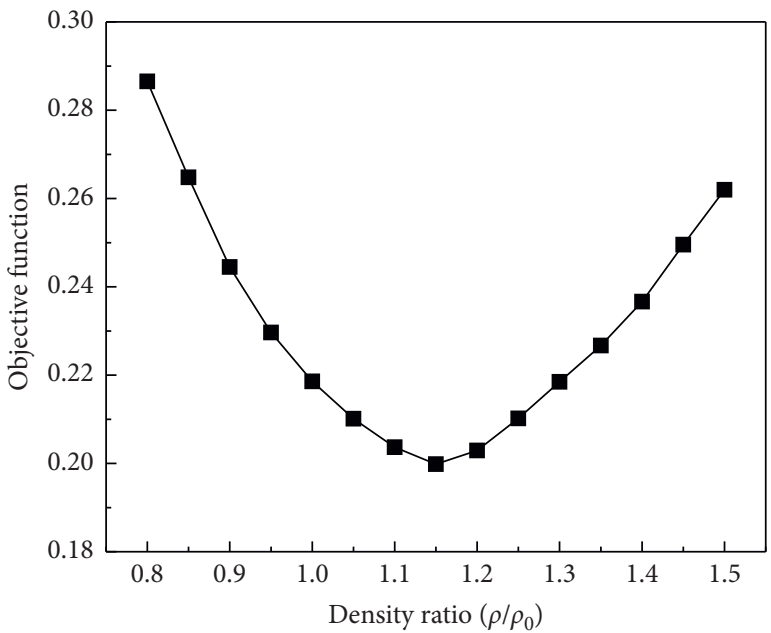

(b)

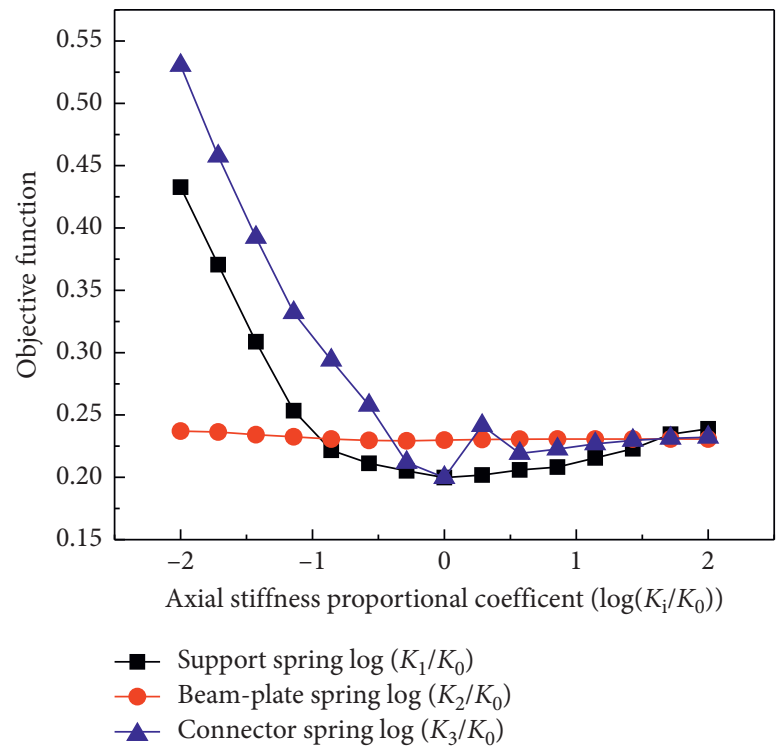

(c)

Figure 18: Physical parameter sensitivity analysis using dynamic data: (a) elastic modulus of the concrete; (b) density of the concrete; (c) axial stiffness of the springs.

and $9^{\#}$ decreased to 0.298 , as shown in Figure 22. The modal parameters calculated using the updated physical parameters were compared with the measured data in Table 7 . The results from the updated models in Case 1 and Case 2 match the results of the experiment models well.

5.5. Damage Detection in the Loading Cases. Instead of adjusting the stiffness properties of all the elements separately, the stiffness can be determined by damage functions, which have to be multiplied by the appropriate factors. This approach decreases the number of unknowns and ensures a physically significant solution [40]. The distribution of the unknown physical properties can be estimated by combining a limited set of damage functions, and the updating parameters are multiplied by the damage functions before combining them [33]. The one-dimensional hierarchical shape function can be defined by

$$
\begin{aligned}
& N_{1}^{\mathrm{e}}\left(x_{1}\right)=\frac{1-x_{1}}{2}, \\
& N_{2}^{\mathrm{e}}\left(x_{1}\right)=\frac{1+x_{1}}{2},
\end{aligned}
$$

where $-1 \leq x_{1} \leq 1, \max \left|N_{2}^{\mathrm{e}}\left(x_{1}\right)\right|=1$.

In the process of damage detection, the element-level damage functions are constructed by mapping the standard shape functions onto "damage elements." These are defined as a series of neighboring elements that are connected by common nodes. The correction parameter $a^{\mathrm{e}}$ of each element is determined by the linear combination of the global 


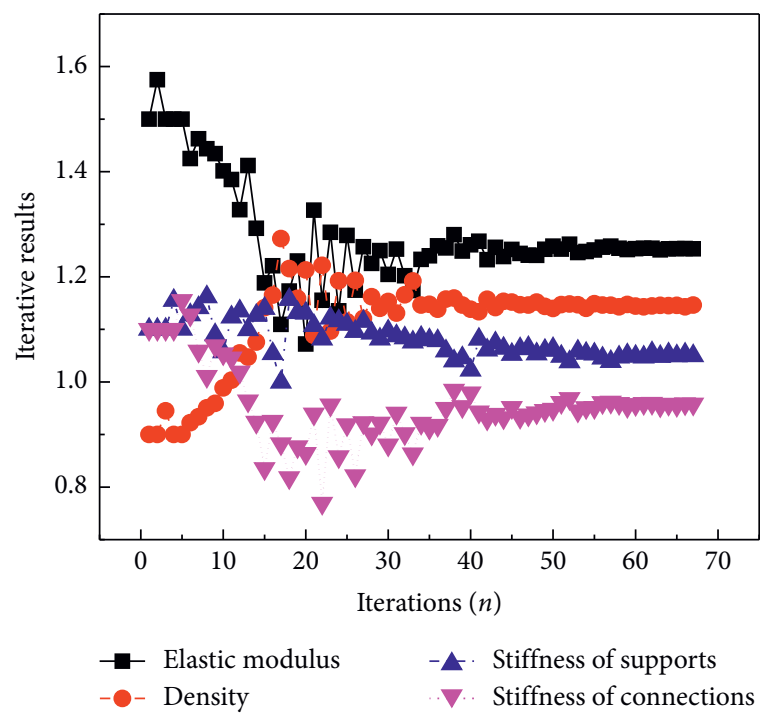

(a)

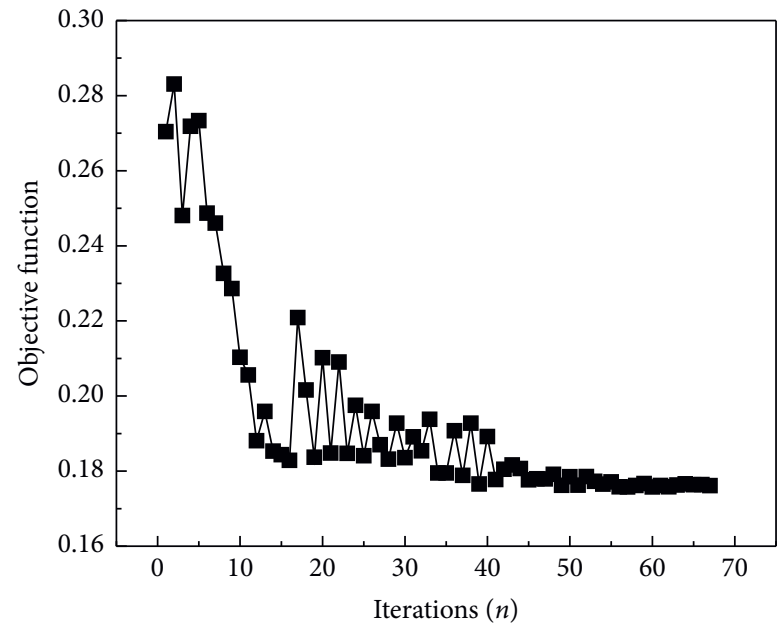

(b)

FIGURE 19: Multiple parameter model updating based on dynamic data: (a) variation of updating parameters; (b) variation of objective function.

TABLE 5: Comparison of initial values and updated values.

\begin{tabular}{lcccc}
\hline Data & Elastic modulus $\left(\mathrm{N} / \mathrm{mm}^{2}\right)$ & Concrete density $\left(\mathrm{kg} / \mathrm{m}^{3}\right)$ & Support stiffness $(\mathrm{kN} / \mathrm{mm})$ & Connector stiffness $(\mathrm{kN} / \mathrm{mm})$ \\
\hline Initial value & 1.5 & 0.9 & 1.1 & 1.1 \\
Updated value & 1.23 & 1.15 & 1.05 & 0.96 \\
\hline
\end{tabular}

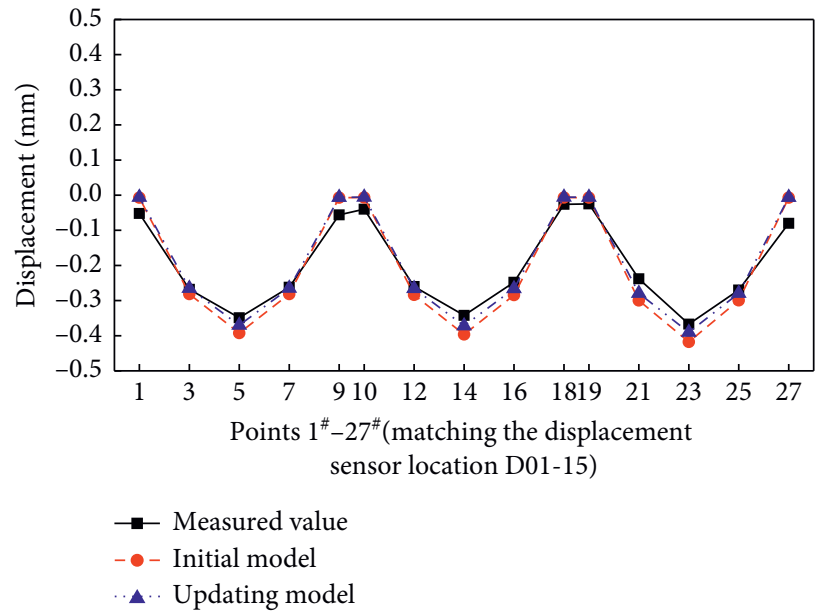

FiguRe 20: Displacement under a uniformly distributed load before and after model updating.

damage functions $N_{\mathrm{i}}$ [40], as shown in the following equation:

$$
a^{e}=\sum_{i=1}^{n_{i}} p_{i} N_{i}\left(x^{e}\right),
$$

where $n_{\mathrm{i}}$ is the number of damage functions $N_{\mathrm{i}}(x), p_{i}$ is the multiplication coefficient, and $x^{e}$ denotes the coordinates of the center point of element $e$. The initial parameter in the undamaged state is characterized by Young's modulus of
$E_{0}=4.31 \times 10^{4} \mathrm{MPa}$, and the elastic modulus is selected as the updating parameter in equation (9). The connection parameter $a^{e}$ lies in the range of $0-1$.

$$
E^{\mathrm{e}}=\left(1-a^{\mathrm{e}}\right) E_{0} .
$$

Each steel girder under the composite deck was divided into 9 FE clusters, as shown in Figure 23(a), and each girder consists of 5 damage element regions, as shown in 
TABle 6: Comparison of modal data before and after model updating.

\begin{tabular}{lcccccc}
\hline \multirow{2}{*}{ Order } & $\begin{array}{c}\text { Measured } \\
\text { Freq. (Hz) }\end{array}$ & Freq. (Hz) & $\begin{array}{c}\text { Initial model } \\
\text { Diff. (\%) }\end{array}$ & MAC & Freq. (Hz) & $\begin{array}{c}\text { Updating model } \\
\text { Diff. (\%) }\end{array}$ \\
\hline 1 & 24.78 & 23.67 & -4.48 & 0.966 & 24.68 & -0.40 \\
2 & 31.26 & 31.30 & 0.13 & 0.959 & 30.79 & -1.51 \\
3 & 56.77 & 62.16 & 9.49 & 0.503 & 59.37 & 0.977 \\
5 & 82.68 & 76.20 & -7.84 & 0.870 & 78.55 & 0.964 \\
7 & 120.01 & 114.42 & -4.66 & 0.755 & 122.52 & -4.99 \\
\hline
\end{tabular}

Note. Diff $=\left(f_{3}-f_{\mathrm{m}}\right) / f_{\mathrm{m}} \times 100 \%, f_{\mathrm{m}}$ is the measured frequency of the composite deck, and $f_{3}$ is the frequency of the initial or updated model.

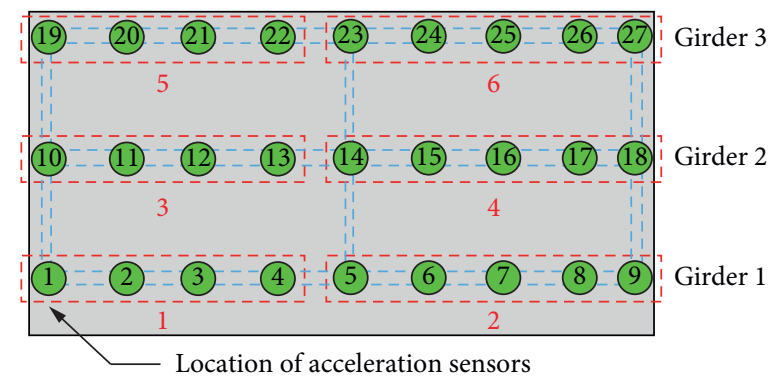

Figure 21: Selection of the updating parameters in Case 2.

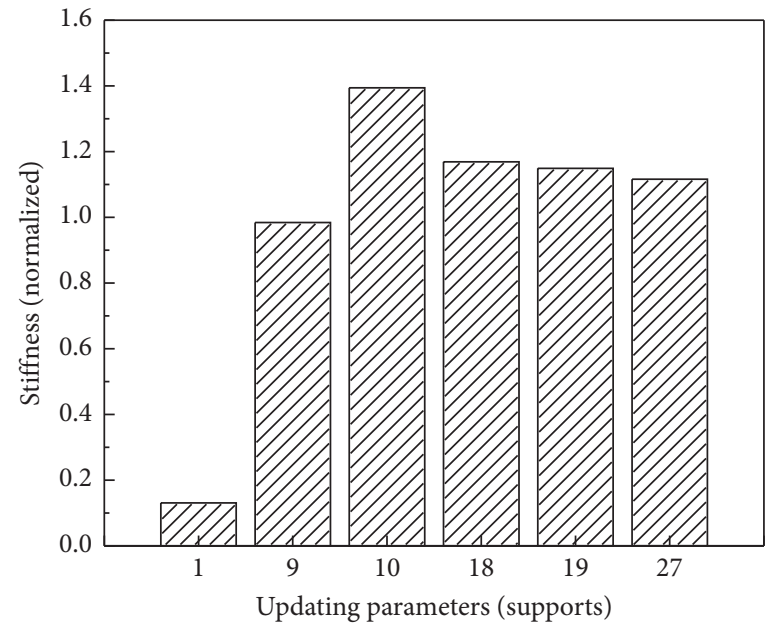

VIII Case 1

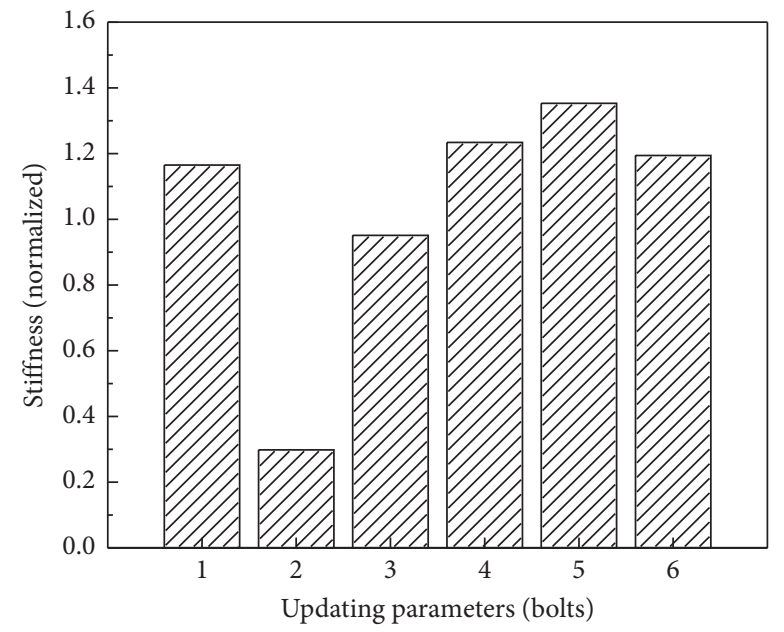

VIIA Case 2

(a)

(b)

FIGURE 22: Updating results of the stiffness degradation: (a) Case 1; (b) Case 2.

TABle 7: Comparison of the identified and tested modal parameters in Case 1 and Case 2.

\begin{tabular}{|c|c|c|c|c|c|c|c|c|}
\hline \multirow[b]{2}{*}{ Mode } & \multicolumn{4}{|c|}{ Case 1} & \multicolumn{4}{|c|}{ Case 2} \\
\hline & Exp. Freq. $(\mathrm{Hz})$ & Updated Freq. (Hz) & Diff. (\%) & MAC & Exp. Freq. (Hz) & Updated Freq. (Hz) & Diff. (\%) & MAC \\
\hline $1^{\text {st }}$ & 18.27 & 16.04 & 12.21 & 0.89 & - & - & - & - \\
\hline $2^{\text {nd }}$ & 23.91 & 22.42 & 6.23 & 0.96 & 24.70 & 23.70 & 4.05 & 0.97 \\
\hline $3^{\text {rd }}$ & 30.76 & 29.61 & 3.74 & 0.86 & 31.71 & 31.13 & 1.83 & 0.83 \\
\hline $6^{\text {th }}$ & 84.43 & 73.47 & -12.98 & 0.60 & 73.93 & 76.01 & 2.81 & 0.89 \\
\hline
\end{tabular}

Note. Diff $=\left(f_{\mathrm{u} 1}-f_{\mathrm{e} 1}\right) / f_{\mathrm{e} 1} \times 100 \%, f_{\mathrm{e} 1}$ is the experimental frequency in Case 1 or Case 2 , and $f_{\mathrm{u} 1}$ is the frequency of the updating model in Case 1 or Case 2 .

Figure 23(b); thus, 5 parameters need to be updated for each girder. A triangular function was used as the shape function in each damage region; instead of modifying all 9 elements separately, the FE model was divided into five damage elements, consisting of three or five neighboring beam elements. Each girder consisted of $n$ connection parameters, 


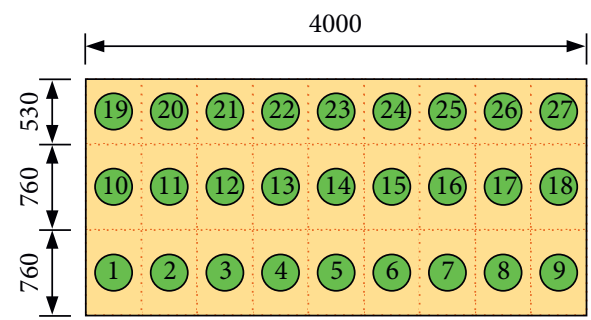

(a)

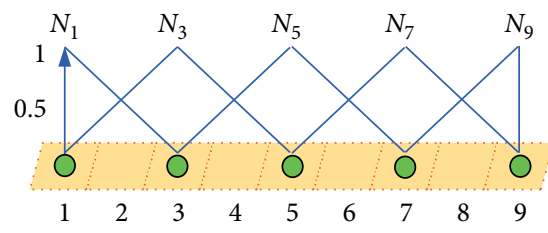

(b)

FIGURE 23: Element division and damage function: (a) element division of the updating model; (b) damage function of a girder.

TABle 8: Comparison of the identified and tested modal parameters for Cases 3, 4, and 5.

\begin{tabular}{|c|c|c|c|c|c|c|c|c|c|c|c|c|}
\hline \multirow[b]{2}{*}{ Mode } & \multicolumn{4}{|c|}{ Case 3} & \multicolumn{4}{|c|}{ Case 4} & \multicolumn{4}{|c|}{ Case 5} \\
\hline & $\begin{array}{c}\text { Exp. Freq. } \\
(\mathrm{Hz})\end{array}$ & $\begin{array}{l}\text { Updated } \\
\text { Freq. }(\mathrm{Hz})\end{array}$ & $\begin{array}{l}\text { Diff. } \\
(\%)\end{array}$ & MAC & $\begin{array}{c}\text { Exp. Freq. } \\
(\mathrm{Hz})\end{array}$ & $\begin{array}{l}\text { Updated } \\
\text { Freq. (Hz) }\end{array}$ & $\begin{array}{l}\text { Diff. } \\
(\%)\end{array}$ & MAC & $\begin{array}{c}\text { Exp. Freq. } \\
(\mathrm{Hz})\end{array}$ & $\begin{array}{l}\text { Updated } \\
\text { Freq. (Hz) }\end{array}$ & $\begin{array}{l}\text { Diff. } \\
(\%)\end{array}$ & MAC \\
\hline $1^{\text {st }}$ & 24.57 & 24.34 & 0.90 & 0.96 & 22.17 & 21.85 & 1.44 & 0.97 & 19.15 & 18.79 & 1.87 & 0.93 \\
\hline $2^{\text {nd }}$ & 31.09 & 31.65 & 1.81 & 0.96 & 30.90 & 31.42 & 1.68 & 0.94 & 28.46 & 29.28 & 2.88 & 0.91 \\
\hline $3^{\mathrm{rd}}$ & 57.56 & 60.36 & 4.86 & 0.63 & 55.24 & 59.78 & 8.21 & 0.59 & 53.70 & 58.93 & 9.74 & 0.61 \\
\hline $5^{\text {th }}$ & 83.09 & 78.11 & 5.99 & 0.91 & 80.02 & 76.43 & 4.49 & 0.89 & 79.74 & 75.86 & 4.87 & 0.83 \\
\hline $7^{\text {th }}$ & 121.13 & 122.09 & 0.79 & 0.79 & 119.56 & 121.43 & 1.56 & 0.78 & 117.25 & 120.85 & 3.07 & 0.75 \\
\hline
\end{tabular}

Note. Diff $=\left(f_{\mathrm{u} 2}-f_{\mathrm{e} 2}\right) / f_{\mathrm{e} 2} \times 100 \%, f_{\mathrm{e} 2}$ is the experimental frequency in Cases 3,4 , or 5 , and $f_{\mathrm{u} 2}$ is the frequency of updating model in Cases 3 , 4 , or 5 .

which can be obtained by multiplying the shape function matrix by the damage coefficient vector, as shown in the following equations:

$$
\begin{aligned}
& \{a\}_{n \times 1}=[N]_{n \times n_{i}}\{P\}_{n_{i} \times 1} \text {, }
\end{aligned}
$$

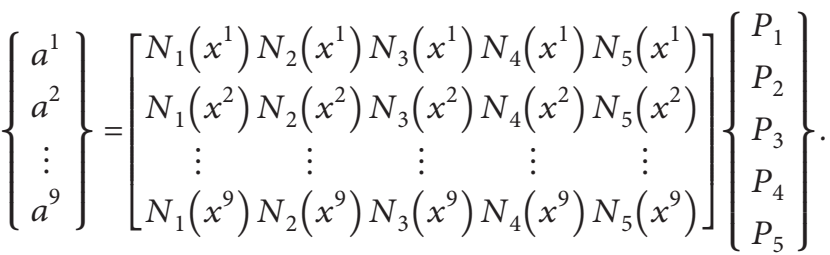

The damage value in each element cluster can be expressed by a shape function; after $P_{\mathrm{i}}$ has been identified, the stiffness reduction coefficient in each element can be calculated. After assembly, five global (linear and stepwise) damage functions $\mathrm{Ni}$ were obtained, and $\mathrm{N}_{1}-\mathrm{N}_{5}$ are plotted in Figure 23(b). For damage detection, the first four identified modes were used to update the model.

With increasing structural damage in Cases 3, 4, and 5 , the stiffness continuously decreased as shown in Figure 21 and Table 8 . Under the same damage case, the stiffness of girder 1 decreased more than that of girder 2 and girder 3 . The updating results under the static loading test were consistent with the crack development (Figure 7). When the structure was still in the linear elastic state, the maximum value of stiffness loss, which was $13.4 \%$, appeared in the $5^{\text {th }}$ zone of girder 1 ; however, the same value became $41.4 \%$ in damage Case 5 , as shown in Figure 24 .

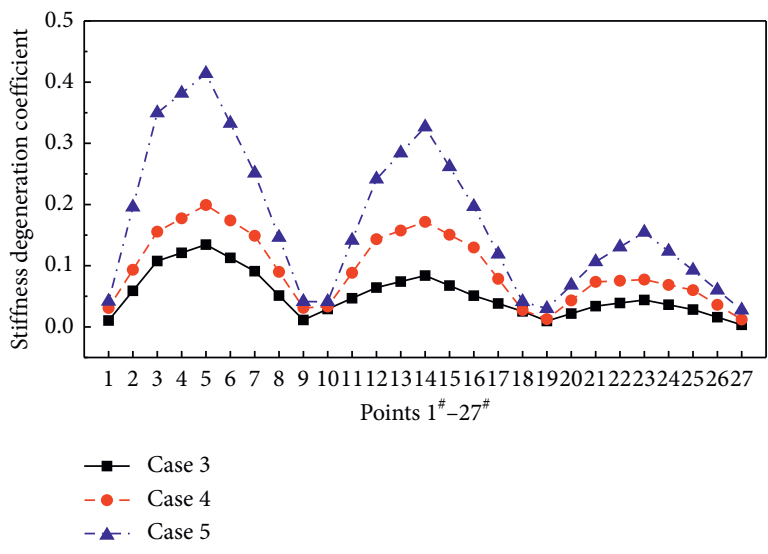

FIgUre 24: Stiffness degradation curve of the steel-concrete composite deck.

\section{Conclusions}

This study proposed two VBDD methods for structure damage identification. An experimental test was firstly conducted by utilizing the non-model-based VBDD method to detect the damage of a scaled steel-concrete composite specimen with various damage settings. Thereafter, based on FE model parameters using Strand7 and MATLAB software, the modelbased VBDD method was utilized to locate and quantify the damage of three calibrated FE models. The proposed procedure is a new application of the damage detection technique for steelconcrete structures. Conclusions from the study are as follows:

(1) The non-model-based VBDD method was utilized for damage identification of the tested steel-concrete 
composite specimen, where the largest MFD obtained by the MRIT was $119.6 \%$ and $89.8 \%$ when the support and connected condition changed, respectively. The MFD also significantly varied under different loading schemes, which can be referred to as an index for damage assessment. This method has the advantages of high accuracy and wide applicability for damage detection of steel-concrete composite structures.

(2) The model-based VBDD method was used for damage identification by conducting numerical analysis. Three different FE models, the beam-shell model, the beam-solid model, and the shell-solid model, were utilized to simulate the behavior of the composite slab. The calculated MFD of the shellsolid FE model was almost identical to the test results, indicating that the performance of the tested composite structure could be accurately predicted by this type of FE model.

(3) Based on the proposed parameter updating program using Strand7 and MATLAB software, the established shell-solid model was calibrated with the selected highly sensitive physical parameters, where the error between calculated and tested $1^{\text {st }}$ natural frequency had been decreased from $4.48 \%$ to $0.40 \%$. Furthermore, the stiffness of the FE model significantly decreased from $86.6 \%$ (under crack stage) to $58.6 \%$ (under failure stage), indicating that the damage of the specimen could be effectively located and quantified with the proposed VBDD method.

\section{Data Availability}

The datasets generated/analyzed in the present study are available upon reasonable request from the corresponding author.

\section{Conflicts of Interest}

The authors declare that there are no conflicts of interest.

\section{Acknowledgments}

The authors sincerely appreciate the funding support provided by the National Natural Science Foundation of China (NSFC) (no. 51878264), the Science and Technology Progress and Innovation Project of the Department of Transportation of Hunan Province (201912), and the Key Research and Development Program of Changsha City (kq1801010).

\section{References}

[1] A. S. Kobayashi, Handbook on Experimental Mechanics, Prentice-Hall, Englewood, CL, USA, 1987.

[2] S. Das, P. Saha, and S. K. Patro, "Vibration-based damage detection techniques used for health monitoring of structures: a review," Journal of Civil Structural Health Monitoring, vol. 6, no. 3, pp. 477-507, 2016.
[3] M. U. Hanif, Z. Ibrahim, K. Ghaedi, H. Hashim, and A. Javanmardi, "Damage assessment of reinforced concrete structures using a model-based nonlinear approach-a comprehensive review," Construction and Building Materials, vol. 192, pp. 846-865, 2018.

[4] A. Rytter, Vibration Based Inspection of Civil Engineering Structures, Ph.D. thesis, Aalborg University, Aalborg, Denmark, 1993.

[5] S. W. Doebling, C. R. Farrar, and M. B. Prime, "A summary review of vibration-based damage identification methods," The Shock and Vibration Digest, vol. 30, no. 2, pp. 91-105, 1998.

[6] J. Kullaa, "Damage detection of the Z24 bridge using control charts," Mechanical Systems and Signal Processing, vol. 17, no. 1, pp. 163-170, 2003.

[7] S. W. Doebling, C. R. Farrar, M. B. Prime, and D. W. Shevitz, "Damage identification and health monitoring of structural and mechanical systems from changes in their vibration characteristics: a literature review," Technical Report LA13070-MS, Los Alamos National Laboratory, Los Alamos, NM, USA, 1996.

[8] H. Sohn, C. R. Farrar, F. M. Hemez et al., "A review of structural health monitoring literature from 1996-2001," Technical Report LA-13976-MS, Los Alamos National Laboratory, Los Alamos, NM, USA, 2003.

[9] J. J. Moughty and J. R. Casas, "A state-of-the-art review of modal-based damage detection in bridges: development, challenges, and solutions," Applied Sciences, vol. 7, no. 7, p. 510, 2017.

[10] Y. B. Yang and J. P. Yang, "State-of-the-Art review on modal identification and damage detection of bridges by moving test vehicles," International Journal of Structural Stability and Dynamics, vol. 18, no. 2, Article ID 1850025, 2018.

[11] Y. Xia, H. Hao, and A. J. Deeks, "Dynamic assessment of shear connectors in slab-girder bridges," Engineering Structures, vol. 29, no. 7, pp. 1475-1486, 2007.

[12] Y. Xia, H. Hao, A. J. Deeks, and X. Zhu, "Condition assessment of shear connectors in slab-girder bridges via vibration measurements," Journal of Bridge Engineering, vol. 13, no. 1, pp. 43-54, 2008.

[13] M. Dilena and A. Morassi, "Vibrations of steel-concrete composite beams with partially degraded connection and applications to damage detection," Journal of Sound and Vibration, vol. 320, no. 1-2, pp. 101-124, 2009.

[14] B. Xu and F. Jiang, "Concrete-steel composite girder bolt loosening monitoring using electromechanical impedance measurements," Earth and Space, pp. 629-634, 2012.

[15] H. Allahyari, I. Rahimi, and A. Allahyari, "Experimental measurement of dynamic properties of composite slabs from frequency response," Measurement, vol. 114, pp. 150-161, 2018.

[16] W. Zhang, J. Li, H. Hao, and H. Ma, "Damage detection in bridge structures under moving loads with phase trajectory change of multi-type vibration measurements," Mechanical Systems and Signal Processing, vol. 87, pp. 410-425, 2017.

[17] T. Wróblewski, M. Jarosińska, M. Abramowicz, and S. Berczyński, "Experimental validation of the use of energy transfer ratio (ETR) for damage diagnosis of steel-concrete composite beams," Journal of Theoretical and Applied Mechanics, vol. 55, no. 1, pp. 241-252, 2017.

[18] H. W. Shih, T. H. T. Chan, and D. P. Thambiratnam, "Structural damage localization in slab-on-girder bridges using vibration characteristics," in Proceedings of the $3 \mathrm{rd}$ 
World Congress on Engineering Asset Management And Intelligent Maintenance System, Beijing, China, October 2008.

[19] R. V. Farahani and D. Penumadu, "Damage identification of a full-scale five-girder bridge using time-series analysis of vibration data," Engineering Structures, vol. 115, pp. 129-139, 2016.

[20] W. Zhao, S. Guo, Y. Zhou, and J. Zhang, "A quantum-inspired genetic algorithm-based optimization method for mobile impact test data integration," Computer-Aided Civil and Infrastructure Engineering, vol. 33, no. 5, pp. 411-422, 2018.

[21] Z. X. Tan, D. P. Thambiratnam, T. H. T. Chan et al., "Damage detection in steel-concrete composite bridge using vibration characteristics and artificial neural network," Structure And Infrastructure Engineering, vol. 16, pp. 1-15, 2019.

[22] X. Wang, R. Hou, Y. Xia et al., "Structural damage detection based on variational bayesian inference and delayed rejection adaptive metropolis algorithm," Structural Health Monitoring, pp. 1-18, Article ID 147592172092125, 2020.

[23] K. Liu and G. De Roeck, "Damage detection of shear connectors in composite bridges," Structural Health Monitoring: An International Journal, vol. 8, no. 5, pp. 345-356, 2009.

[24] W.-X. Ren, Z.-S. Sun, Y. Xia, H. Hao, and A. J. Deeks, "Damage identification of shear connectors with wavelet packet energy: laboratory test study," Journal of Structural Engineering, vol. 134, no. 5, pp. 832-841, 2008.

[25] J. Li, H. Hao, and H.-P. Zhu, "Dynamic assessment of shear connectors in composite bridges with ambient vibration measurements," Advances in Structural Engineering, vol. 17, no. 5, pp. 617-637, 2014.

[26] C. Bao, H. Hao, Z. Li, and X. Zhu, "Time-varying system identification using a newly improved HHT algorithm," Computers and Structures, vol. 87, no. 23-24, pp. 1611-1623, 2009.

[27] J. Li, H. Hao, K. Fan, and J. Brownjohn, "Development and application of a relative displacement sensor for structural health monitoring of composite bridges," Structural Control and Health Monitoring and Health Monitoring, vol. 22, no. 4, pp. 726-742, 2015.

[28] J. Li and H. Hao, "Damage detection of shear connectors under moving loads with relative displacement measurements," Mechanical Systems and Signal Processing, vol. 60-61, pp. 124-150, 2015.

[29] U. Dackermann, J. Li, R. Rijal, and K. Crews, "A dynamicbased method for the assessment of connection systems of timber composite structures," Construction and Building Materials, vol. 102, pp. 999-1008, 2016.

[30] Ministry of Housing and Urban-Rural Development of China, Code For Design of Concrete Structures (GB 50010-2010), China Architecture and Building Press, Beijing, China, 2010.

[31] Y. Jiang, "Sub-structural modal flexibility integration theory and experiment research for bridge deck identification," pp. 87-102, Hunan University, Changsha, China, 2015, Master Thesis.

[32] R. Clough and J. Penzien, Dynamics of Structure, pp. 175-176, McGraw-Hill Book Co., Berkeley, CA, USA, 1975.

[33] F. N. Catbas, D. L. Brown, and A. E. Aktan, "Use of modal flexibility for damage detection and condition assessment: case studies and demonstrations on large structures," Journal of Structural Engineering, vol. 132, no. 11, pp. 1699-1712, 2006.

[34] Y. Zhou, J. Prader, J. Weidner, N. Dubbs, F. Moon, and A. E. Aktan, "Structural identification of a deteriorated reinforced concrete bridge," Journal of Bridge Engineering, vol. 17, no. 5, pp. 774-787, 2012.
[35] R. J. Allemang and D. L. Brown, "A unified matrix polynomial approach to modal identification," Journal of Sound and Vibration, vol. 211, no. 3, pp. 301-322, 1998.

[36] Y. Zhou, T. Chen, Y. Pei et al., "Static load test on progressive collapse resistance of fully assembled precast concrete frame structure," Engineering Structures, vol. 200, Article ID 109719, 2019.

[37] A. S. Genikomsou and M. A. Polak, "Finite element analysis of punching shear of concrete slabs using damaged plasticity model in ABAQUS," Engineering Structures, vol. 98, no. 1, pp. 38-48, 2015.

[38] B. Jaishi, H.-J. Kim, M. K. Kim, W.-X. Ren, and S.-H. Lee, "Finite element model updating of concrete-filled steel tubular arch bridge under operational condition using modal flexibility," Mechanical Systems and Signal Processing, vol. 21, no. 6, pp. 2406-2426, 2007.

[39] J. E. Mottershead, M. Link, and M. I. Friswell, "The sensitivity method in finite element model updating: a tutorial," $\mathrm{Me}$ chanical Systems and Signal Processing, vol. 25, no. 7, pp. 2275-2296, 2011.

[40] A. Teughels, J. Maeck, and G. De Roeck, "Damage assessment by FE model updating using damage functions," Computers \& Structures and Structures, vol. 80, no. 25, pp. 1869-1879, 2002. 